\title{
Accurate Measurement of Systemic Oxygen Consumption in Ventilated Children with Congenital Heart Disease
}

\author{
Jia Li \\ University of Alberta \\ Canada
}

\section{Introduction}

Measuring systemic oxygen consumption $\left(\mathrm{VO}_{2}\right)$ is a fundamental part of hemodynamic and oxygen transport assessment when using the Fick principle. This measure is pivotal for children with congenital heart disease, at cardiac catheterization and in the Intensive Care Unit (ICU) after cardiopulmonary bypass surgery (CPB). According to the direct Fick principle (Fick, 1870), $\mathrm{VO}_{2}$ may be combined with the difference between arterial and venous oxygen content, and the pressure gradient, to allow the calculation of each parameter of systemic hemodynamics and oxygen transport. Parameters that may be calculated include systemic and pulmonary blood flows (Qs and Qp) and resistances (SVR and PVR), systemic oxygen delivery $\left(\mathrm{DO}_{2}\right)$, and oxygen extraction ratio $\left(\mathrm{ERO}_{2}\right)$. Importantly, these parameters can be derived in a variety of simple or complex circulations in congenital heart defects before and after surgical repair or palliation, including 1) biventricular circulation with or without left to right or right to left shunt (Li, Hoschtitzky et al. 2004; Li, Schulze-Neick et al. 2000; Schulze-Neick, Li et al. 2001; Schulze-Neick, Li et al. 2002), 2) functionally single ventricular circulation such as hypoplastic left heart syndrome before and after the Norwood procedure (Li, Zhang et al. 2006; Li, Zhang et al. 2006; Li, Zhang et al. 2007; Li, Zhang et al. 2007; Li, Zhang et al. 2008), and 3) one-and-a-half ventricular circulation such as after the bidirectional cavopulmonary shunt operation (Hoskote, Li et al. 2004; Li, Hoskote et al. 2005).

If $\mathrm{VO}_{2}$ needs to be measured, then accuracy of the measurement cannot be overemphasized (Kendrick, West et al. 1988; Laitinen and Rasanen 1998; Shanahan, Wilson et al. 2003). Any error in $\mathrm{VO}_{2}$ measurement will translate directly into an equivalent magnitude of underestimation or over-estimation of hemodynamics and oxygen transport parameters, which may misdirect surgical and clinical treatment strategies. Prognostic cardiac catheterization is often used for evaluation of systemic and pulmonary blood flows and vascular resistances, particularly pulmonary vascular resistance, in patients with primary or secondary pulmonary hypertension, and in patients with functionally single ventricular abnormalities undergoing staged surgical palliations. In this latter group, elevated pulmonary vascular resistance is a risk factor for poor outcome (Gentles, Gauvreau et al. 1997; Gentles, Mayer et al. 1997; Mair, Hagler et al. 1990), emphasizing the need for accurate hemodynamic assessment before staged palliations. 
In ICU patients, the importance of the accurate measurement of $\mathrm{VO}_{2}$ has been increasingly realized in the past decade or two. Significant alterations in systemic oxygen transport and the contribution of $\mathrm{VO}_{2}$ in the impaired balance of oxygen transport during the early postoperative period after CPB are now better understood (Chiara, Giomarelli et al. 1987; Li, Hoschtitzky et al. 2004; Li, Schulze-Neick et al. 2000; Li, Zhang et al. 2007; Li, Zhang et al. 2007; Oudemans-van Straaten, Jansen et al. 1996). $\mathrm{VO}_{2}$ has its own meaning in the balance of oxygen transport, which has been largely ignored. A hypermetabolic response with increased $\mathrm{VO}_{2}$ occurs in patients after $\mathrm{CPB}$, due mainly to 1) a systemic inflammatory response (Li, Hoschtitzky et al. 2004; Oudemans-van Straaten, Jansen et al. 1996), 2) rewarming from hypothermic CPB and fever (Li, Hoschtitzky et al. 2004; Li, SchulzeNeick et al. 2000), and 3) the use of inotropes ( $\mathrm{Li}$, Zhang et al. 2006). The increase in $\mathrm{VO}_{2}$ is an important contributor to the imbalance of oxygen transport in the early postoperative period, when cardiac function and oxygen delivery are depressed due to myocardial injury by surgery and ischemia-reperfusion (Li, Zhang et al. 2006; Li, Zhang et al. 2007; Wernovsky, Wypij et al. 1995). $\mathrm{VO}_{2}$ varies greatly between patients and within individual patients over time. Variation in $\mathrm{VO}_{2}$ results from varied circulatory, metabolic, and hormonal responses to CPB (Li, Hoschtitzky et al. 2004; Oudemans-van Straaten, Jansen et al. 1996), from patient body temperature (Li, Hoschtitzky et al. 2004; Li, Schulze-Neick et al. 2000;), and from pharmacological ( $\mathrm{Li}$, Zhang et al. 2006) and ventilator manipulations (Li, Hoskote et al. 2005; Li, Zhang et al. 2008) (please see section 4 for details). In this dynamic milieu, continuous or repeated monitoring of $\mathrm{VO}_{2}$ is necessary to reflect changes over time.

Accurate measurement of $\mathrm{VO}_{2}$ allows precise assessment of systemic hemodynamics and oxygen transport parameters in varied circulations after complete repair or palliations ( $\mathrm{Li}$, Hoschtitzky et al. 2004; Li, Hoskote et al. 2005; Li, Schulze-Neick et al. 2000; Li, Zhang et al. 2006; Li, Zhang et al. 2006; Li, Zhang et al. 2007; Li, Zhang et al. 2007; Li, Zhang et al. 2008; Schulze-Neick, Li et al. 2001; Schulze-Neick, Li et al. 2002). Actual measurements are superior to the indirect indicators, such as blood pressure and arterial and venous oxygen saturations that are most commonly used in postoperative management. Superiority of actual measurements is seen particularly clearly after the Norwood procedure, when profound hemodynamic instability and oxygen transport imbalance occurs. Furthermore, actual measurements of hemodynamics and oxygen transport parameters are fundamental to bedside physiological research on factors affecting the imbalance of oxygen transport, research aimed at improving the management of critically ill children. With direct and continuous measurement of $\mathrm{VO}_{2}$ using state-of-the-art technique respiratory mass spectrometry, we have conducted extensive studies in neonates after the Norwood procedure (Li, Zhang et al. 2006; Li, Zhang et al. 2006; Li, Zhang et al. 2007; Li, Zhang et al. 2007; Li, Zhang et al. 2008; Li, Zhang et al. 2008; Li, Zhang et al. 2008; Li, Zhang et al. 2008). We use the Norwood circulation and physiology in this Chapter as a model to understand oxygen transport and the factors affecting oxygen kinetics in children after CPB.

The objectives of this chapter are two-fold. 1) To review the currently available techniques of $\mathrm{VO}_{2}$ measurement, including published predictive equations and indirect Fick principle using themodilution, their advantages and disadvantages, with special emphasis on respiratory mass spectrometry to assess $\mathrm{VO}_{2}$ in children undergoing cardiac cauterization and after CPB in the ICU. 2) Using the Norwood physiology as the model to introduce the concept of oxygen transport and further emphasize the importance of direct and continuous 
measurement of $\mathrm{VO}_{2}$ in both clinical care and research in children with congenital heart disease before and after CPB.

\section{The inaccurate techniques for measurement of $\mathrm{VO}_{2}$}

\subsection{The inaccuracies of predictive equations}

Although techniques for metabolic monitoring using indirect calorimetry or respiratory mass spectrometry are available for the direct measurement of $\mathrm{VO}_{2}$, it is still common practice to estimate $\mathrm{VO}_{2}$ values from tables or published predictive equations (LaFarge and Miettinen 1970; Lindahl 1989; Lundell, Casas et al. 1996; Wessel, Rorem et al. 1969). Despite attempts to improve the accuracy of estimated $\mathrm{VO}_{2}$ values, large discrepancies are still observed between measured and estimated values (Laitinen and Rasanen 1998; Shanahan, Wilson et al. 2003; Wolf, Pollman et al. 1998). Such discrepancies present challenges in the clinical application of predictive equations e.g., in the catheterization laboratory setting, because subsequent hemodynamic calculations will be impaired. In ICU patients during the early postoperative period after $\mathrm{CPB}$, estimation of $\mathrm{VO}_{2}$ is even further exposed to inaccuracies due to significant variability of $\mathrm{VO}_{2}$ between and within patients over time ( $\mathrm{Li}$, Zhang et al. 2006; Li, Zhang et al. 2006; Li, Zhang et al. 2007; Li, Zhang et al. 2008). Furthermore, estimating $\mathrm{VO}_{2}$ by predictive equations gives a single value for a given patient and makes no provision for the dynamic patient milieu that is inevitable in the early postoperative period (Li, Zhang et al. 2006; Li, Zhang et al. 2006; Li, Zhang et al. 2007; Li, Zhang et al. 2008).

We have compared results from four commonly used equations for estimating $\mathrm{VO}_{2}$ (LaFarge and Miettinen 1970; Lindahl 1989; Lundell, Casas et al. 1996; Wessel, Rorem et al. 1969) against $\mathrm{VO}_{2}$ measured directly by respiratory mass spectrometry. Both the equations and the direct measurements were applied to children with congenital heart defects, during cardiac catherization and in the ICU after CPB. We found poor agreement between the direct measurements and all estimated values, especially in children younger than 3 years of age and in the ICU patients (Li, Bush et al. 2003; Rutledge, Bush et al. 2010).

\subsection{1 $\mathrm{VO}_{2}$ values during cardiac catheterization versus in the ICU after CPB}

In patients undergoing cardiac catheterization, there is a general over-estimation of $\mathrm{VO}_{2}$ introduced by the equations (Figure 1) (Li, Bush et al. 2003). The conditions of conscious sedation with spontaneous ventilation were used to generate the predictive equations decades ago. In contrast in current practice, general anesthesia and mechanical ventilation are used in most children undergoing cardiac catheterization. General anesthesia and muscle relaxants with mechanical ventilation may decrease the cardiopulmonary work and metabolic rate, resulting in a reduction in $\mathrm{VO}_{2}$ of up to 20 to $30 \%$.(Nisbet, Dobbinson et al. 1973; Westenskow, Jordan et al. 1978)

In the ICU patients, a general under-estimation of $\mathrm{VO}_{2}$ is introduced by the equations, with very poor agreement to actual measurements, as the equations were generated in preoperative patients undergoing cardiac catheterization ( $\mathrm{Li}$, Bush et al. 2003). After CPB, $\mathrm{VO}_{2}$ is significantly increased and highly variable between patients and within each patient (Figure 2) (Li, Zhang et al. 2006; Li, Zhang et al. 2007; Li, Zhang et al. 2008). Thus, the direct measurement of $\mathrm{VO}_{2}$ is essential for these patients; continuous or repeated measurements are also essential to reflect the dynamic changes in these patients that occur over time. 

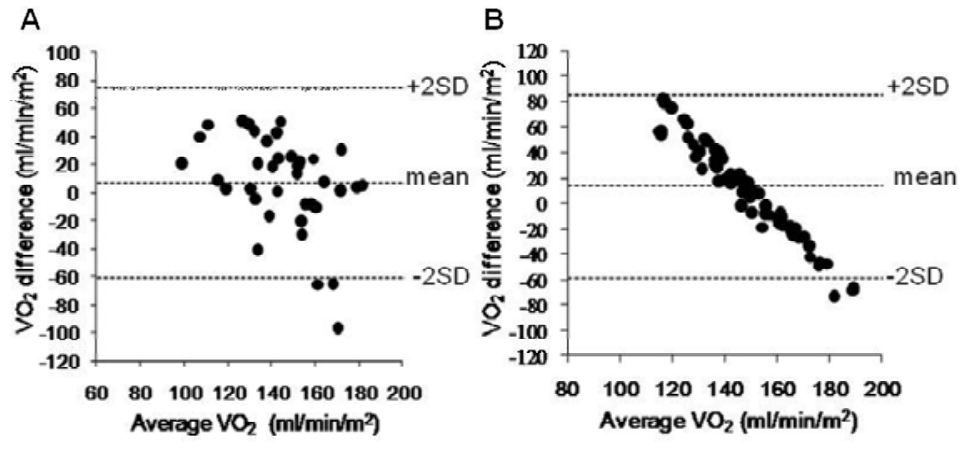

C

D
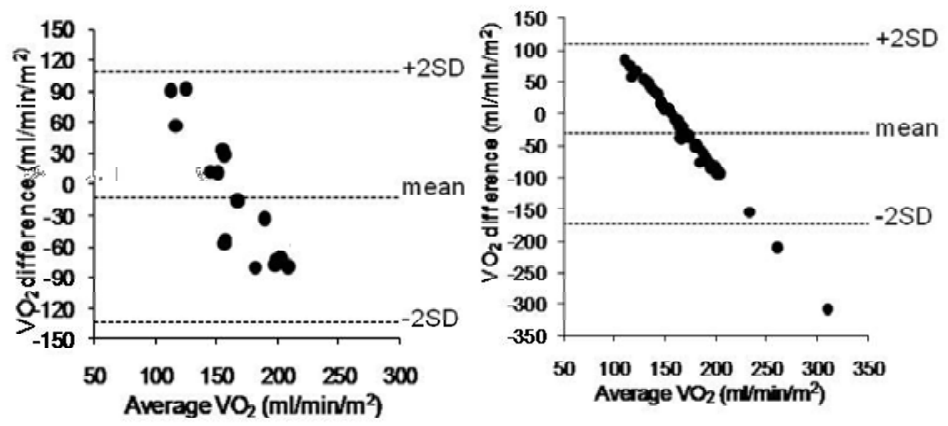

Fig. 1. Agreement of measured and estimated $\mathrm{VO}_{2}$. Measured $\mathrm{VO}_{2}$ minus estimated $\mathrm{VO}_{2}$ is plotted against average $\mathrm{VO}_{2}$; in patients undergoing cardiac catheterization, (A) using the LaFarge equation and (B) the Wessel equation; and after cardiac surgery in the ICU, (C) using the LaFarge equation and (D) the Wessel equation .

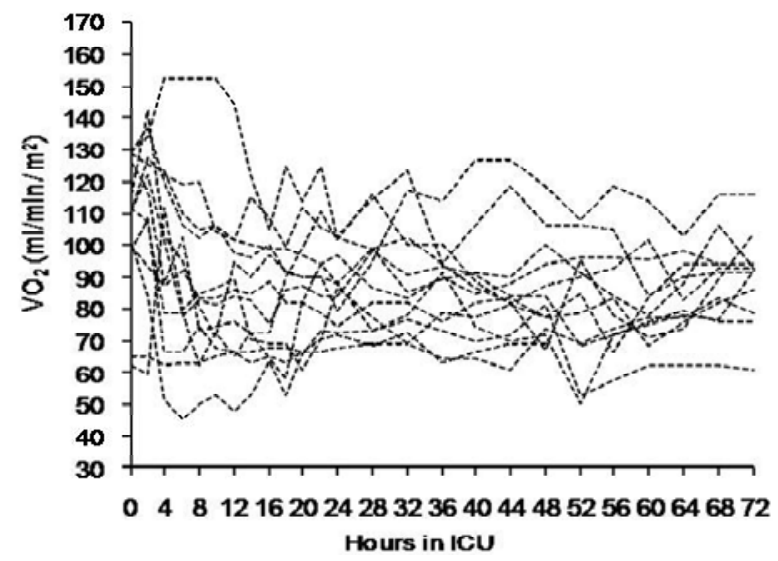

Fig. 2. Measured $\mathrm{VO}_{2}$ by respiratory mass spectrometry in 14 neonates in the first 72 hours after the Norwood procedure 


\subsection{2 $\mathrm{VO}_{2}$ values in patients $>3$ years old versus $\leq \mathbf{3}$ years old}

Of the equations we tested initially, the LaFarge equation is the most commonly used and gives the closest estimation to measured results with the lowest bias and limits of agreement (Li, Bush et al. 2003). However, despite the fact that the LaFarge equation was generated and intended for use in patients between 3 and 40 years of age, it is applied in patients of all ages. With advances in surgical techniques and perioperative management, increasing numbers of younger patients with complex congenital heart defects, such as functionally single ventricular abnormalities, undergo cardiac surgery. This in turn increases the need for diagnostic cardiac catheterization in children younger than 3 years, often with the single goal of accurately evaluating pulmonary vascular resistance.

Our initial study, comparing measured and estimated $\mathrm{VO}_{2}$, excluded patients whose ages fell outside the range used in the derivation of LaFarge equation, that is, younger than 3 years. We revisited the data to compare estimates of $\mathrm{VO}_{2}$ in patients younger than 3 years to the earlier data from patients older than 3 years of age. Estimations were significantly poorer in the group younger than 3 years, with a bias of $55 \mathrm{~mL} / \mathrm{min} / \mathrm{m}^{2}$, compared to a bias of $11 \mathrm{~mL} / \mathrm{min} / \mathrm{m}^{2}$ in the older group. The limits of agreements were -42 to +153 $\mathrm{mL} / \mathrm{min} / \mathrm{m}^{2}$ for children $<3$ years versus -39 to $+61 \mathrm{~mL} / \mathrm{kg} / \mathrm{m}^{2}$ for those $\geq 3$ years (Figure 3) (Rutledge, Bush et al. 2010)
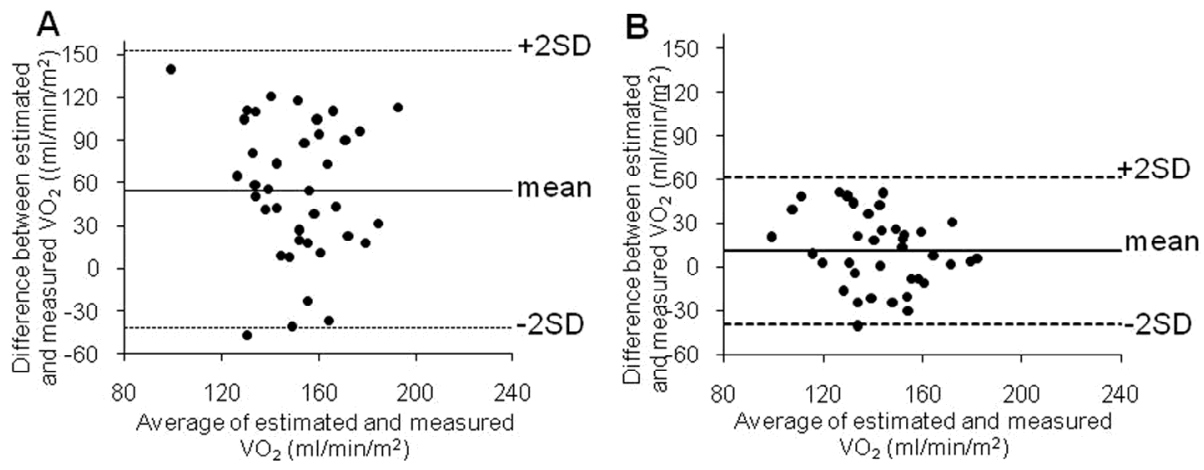

Fig. 3. Agreement of measured and estimated $\mathrm{VO}_{2}$ during cardiac catheterization in patients (A) $<3$ years old and $(\mathrm{B})>3$ years old.

The LaFarge equation (LaFarge and Miettinen 1970) includes a logarithmic transformation of age for male patients (equation 1) and for female patients (equation 2).

$$
\begin{aligned}
& \mathrm{VO}_{2}\left(\mathrm{~mL} / \mathrm{min} / \mathrm{m}^{2}\right)=138.1-(11.49 \times \text { logeage })+(0.378 \times \text { heart rate }) \\
& \mathrm{VO}_{2}\left(\mathrm{~mL} / \mathrm{min} / \mathrm{m}^{2}\right)=138.1-(17.04 \times \text { logeage })+(0.378 \times \text { heart rate })
\end{aligned}
$$

The logarithmic transformation of age intrinsically results in a faster increase in estimated $\mathrm{VO}_{2}$ as age decreases, particularly within the first 3 years of life (Figure $4 \mathrm{~A}$ ). Interestingly, the directly measured $\mathrm{VO}_{2}$ has almost exactly the opposite trend, being lowest in the youngest patients and quickly increasing in the first 3 to 4 years (Figure 4B). As a result, the errors of estimated $\mathrm{VO}_{2}$ are dramatically related to age (Figure $4 \mathrm{C}$ ). The reasons for lower $\mathrm{VO}_{2}$ in younger children remain unclear, but body composition may be a factor. In 
particular, 'fat mass' is relatively higher in younger children (Fomon, Haschke et al. 1982; Moukarzel, Salas et al. 2003) and $\mathrm{VO}_{2}$ in fat mass is about 20 times lower than in muscular mass (Moukarzel, Salas et al. 2003).
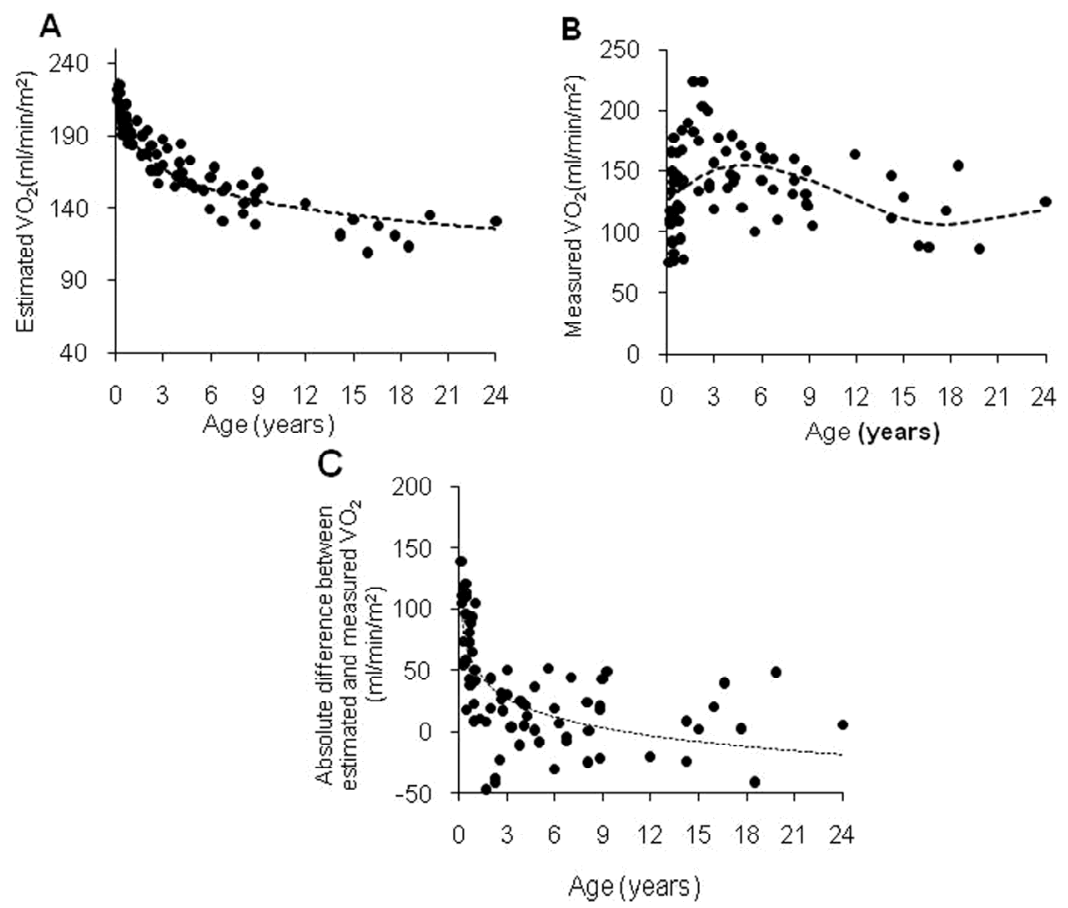

Fig. 4. The trends in relation to age of (A) estimated $\mathrm{VO}_{2}$, (B) measured $\mathrm{VO}_{2}$, and (C) their difference, in 75 patients undergoing cardiac catheterization.

We conclude that estimation of $\mathrm{VO}_{2}$ is unacceptably inaccurate for clinical decision-making and research. Direct measurement of $\mathrm{VO}_{2}$ is appropriate for young children with congenital heart defects undergoing cardiac catheterization and in the ICU after CPB. Direct and continuous measurement of $\mathrm{VO}_{2}$ is essential, particularly in those younger than 3 years and in the early postoperative period after $\mathrm{CPB}$.

\subsection{Inadequacy of the reverse Fick method}

$\mathrm{VO}_{2}$ can also be calculated by the reverse Fick method from the cardiac output, directly measured by the thermodilution technique, for example. This method has obvious limitations for clinical application in patients with congenital heart defects. First, the calculation is clearly intermittent. Second, the presence of intracardiac shunting and tricuspid regurgitation can significantly affect the accuracy of the calculation. Most important, certain complex circulations preclude the use of the thermodilution technique (e.g., after the Norwood procedure, bidrectional caval pulmonary shunt, or the Fontan operation), because of anatomical (e.g., parallel systemic and pulmonary circulations) and methodological (e.g., inadequate mixing) limitations. 


\section{Direct measurement of $\mathrm{VO}_{2}$ using respiratory mass spectrometry}

The concept of mass spectrometry (measuring fractional proportions of substances in a mixture, according to their molecular mass-charge ratios) was first introduced at the end of the $19^{\text {th }}$ century. The recruitment of mass spectrometry into respiratory physiology in the 1940s, and its subsequent refinement over the decades, has established a 'state-of-the-art' method for measuring $\mathrm{VO}_{2}$ using highly accurate and rapid multiple gas analysis. The mixed expirate method (Davies and Denison 1979) enabled use of the mass spectrometer alone to measure metabolic gas exchange and ventilation volume. This technique has been used widely to measure $\mathrm{VO}_{2}$ in a broad spectrum of clinical and experimental conditions. We have adapted the method to continuously measure $\mathrm{VO}_{2}$ with a variety of pediatric ventilators and anesthesia ventilators before, during, and after CPB, using the AMIS 2000 Medical Respiratory Mass Spectrometer System (Innovision A/C Odense, Denmark). Our combination of techniques and equipment makes respiratory mass spectrometry a unique and powerful tool in multiple settings: in the cardiac catheterization laboratory (SchulzeNeick, Li et al. 2002 ; Shekerdemian, Bush et al. 1997; Shekerdemian, Bush et al. 1997), in the operating room (Li, Stokoe et al. 2004), and in the ICU (Li, Hoschtitzky et al. 2004; Li, Schulze-Neick et al. 2000; Li, Zhang et al. 2006; Li, Zhang et al. 2006; Li, Zhang et al. 2007; Li, Zhang et al. 2007; Li, Zhang et al. 2008; Schulze-Neick, Li et al. 2001).

\subsection{Principles of mass spectrometry}

Mass spectrometers analyze substances in the gas phase by performing a sequence of five operations: 1) accept and vaporize a minute controlled quantity of sample; 2) reduce the sample vapor to a very low pressure; 3 ) ionize a representative part of the vapor; 4) separate the ionized particles produced, according to their mass-to-charge ratio; and 5) read the abundance of particles at specific values of the mass-to-charge ratio.

\subsection{Hardware design}

Features of a mass spectrometer are outlined in Figure 5.

A Teflon capillary tubing (A) with an internal diameter $0.3 \mathrm{~mm}$ and a length of 3 to $6 \mathrm{~m}$ provides the gas transport from the sampling site (B) to the vacuum system. There are three sample inlets, one for the on-line continuous monitoring of $\mathrm{O}_{2}$ and $\mathrm{CO}_{2}$ fractional concentrations, the other two for the inspiratory and expiratory gas sampling. The gas sample at atmospheric pressure is drawn at a sampling rate of 10 to $20 \mathrm{~mL} / \mathrm{min}$ down the tubing (A), passing through the three static electro-magnetic valves (C), which are selected in turn as appropriate to the sequence of gas analysis needed for the metabolic calculations. The sample is drawn by the inlet rotary vacuum pump (D) into the sample chamber (E), and all but a small fraction of it is pumped away continuously at the low-pressure end of the inlet tubing. The turbo molecular pump (F), supported by a second backing rotary pump $(\mathrm{G})$, provides a very high vacuum environment of around $5 \times 10^{-7} \mathrm{mBar}$ in the dispersion chamber $(\mathrm{H})$, housing ionization chamber $(\mathrm{I})$, mass filter $(\mathrm{J})$, and ion detector $(\mathrm{K})$. Thus, the high vacuum provided by the turbo molecular pump draws the remaining gas sample through the molecular leak (L) into the ionization chamber, where the gas molecules are ionized. The ions are focused into a tight beam, enter the aperture of the quadrupole mass filter, and are separated by the quadrupole mass filter (J). The use of appropriate voltages in this field allows only ions of a definite mass interval to pass and reach the ion detector $(\mathrm{K})$, 
suppressing the inevitable 'noise' which would otherwise be created by the contaminants that cross the mass filter as a result of scatter. The ions are then collected and pre-amplified in a current-voltage pre-amplifier prior to signal processing. The resulting signal is therefore made as pure as possible before being amplified by the secondary electron multiplier (SEM). Amplification enables a higher sensitivity and faster operation. The resulting output of the detection unit is proportional to the ion current, which in turn is proportional to the partial pressure of the gas species. (Pressures indicated are at normal operating conditions).

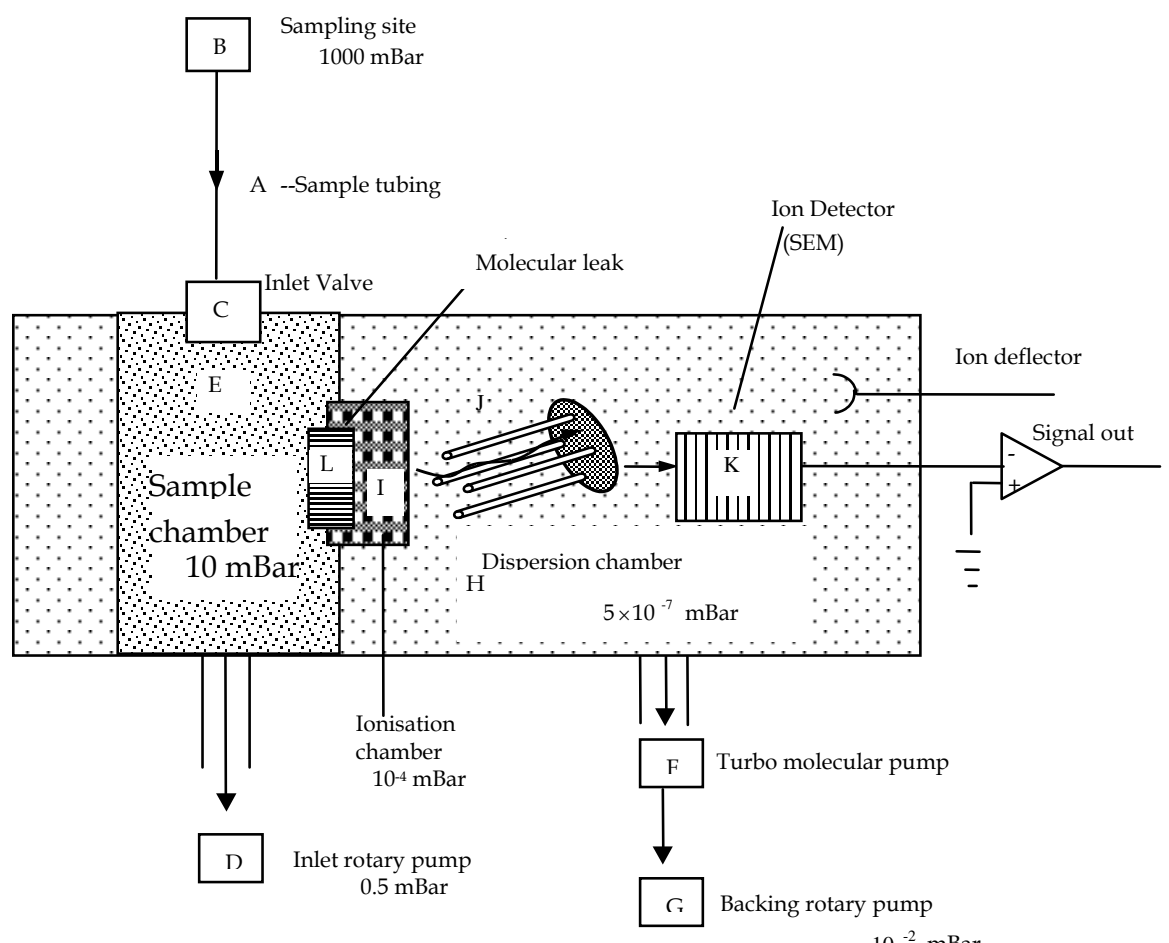

Fig. 5. Design of AMIS 2000 respiratory mass spectrometer.

\subsection{The measurement of $\mathrm{VO}_{2}$}

The mass spectrometer measures metabolic gas exchange by the 'inert gas dilution method'. 'A known mass flow of a marker gas is injected into expired gas upstream of a mixing box, and the resulting gas composition downstream used to deduce the mass flows of all its components' (Davies and Denison 1979). $\mathrm{VO}_{2}$ is then calculated every 30 seconds as:

$$
\mathrm{VO}_{2}(\mathrm{STPD})=\mathrm{V}_{\mathrm{Tr}}(\mathrm{STPD}) \bullet\left[\mathrm{F}_{\mathrm{IO} 2} \bullet\left(1-\mathrm{F}_{\mathrm{MCO} 2}-\mathrm{F}_{\mathrm{MTr}}\right)-\mathrm{F}_{\mathrm{MO} 2} \bullet\left(1-\mathrm{F}_{\mathrm{ICO} 2}-\mathrm{F}_{\mathrm{ITr}}\right)\right] / \mathrm{D}
$$

$\mathrm{D}=\mathrm{F}_{\mathrm{MTr}} \bullet\left(1-\mathrm{F}_{\mathrm{IO} 2}-\mathrm{F}_{\mathrm{ICO} 2}\right)-\mathrm{F}_{\mathrm{Itr}} \bullet\left(1-\mathrm{F}_{\mathrm{MO} 2}-\mathrm{F}_{\mathrm{MCO} 2}\right)$

$\mathrm{V}_{\mathrm{Tr}}=$ added flow of indicator gas (tracer, Argon)

$\mathrm{F}_{\mathrm{IO} 2}, \mathrm{~F}_{\mathrm{ICO} 2}, \mathrm{~F}_{\mathrm{Itr}}=$ constant fractional concentrations of $\mathrm{O}_{2}, \mathrm{CO}_{2}$ and tracer gas in inspired air 
$\mathrm{F}_{\mathrm{MO} 2}, \mathrm{~F}_{\mathrm{MCO} 2}, \mathrm{~F}_{\mathrm{MTr}}=$ measured fractional concentrations of $\mathrm{O}_{2}, \mathrm{CO}_{2}$ and tracer gas at the outlet of the mixing chamber

STPD $=$ Standard temperature and pressure dry.

\subsection{Setup of respiratory mass spectrometer in the cardiac catheterization laboratory with anesthesia ventilators}

Accurate measurement of minute ventilation relies on the complete collection of expired gas and therefore a leak-free circuit. Ideally, patients are intubated with cuffed endotracheal tubes. Precise $\mathrm{VO}_{2}$ measurement requires a steady-state period, thus patients are sedated and paralyzed to obviate the confounding effects of movement, agitation, and pain on $\mathrm{VO}_{2}$. We have adapted the AMIS2000 respiratory mass spectrometer in the cardiac catheterization laboratory to anesthesia ventilators with a partial rebreathing system (Figure 6).

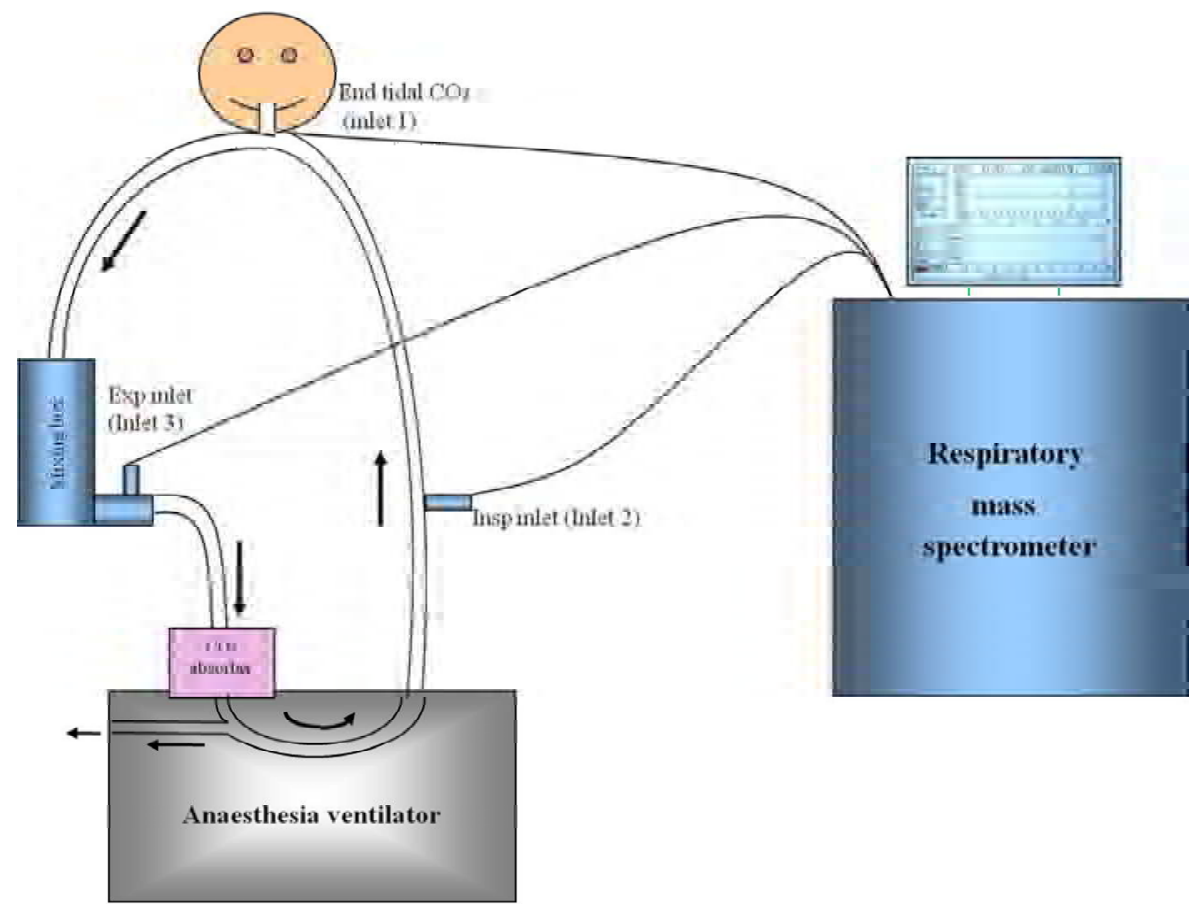

Fig. 6. The setup of the AMIS2000 respiratory mass spectrometer sampling inlets, mixing box, and the circuit of the anesthesia ventilator in the cardiac catheterization laboratory.

Most children undergoing cardiac catheterization are paralyzed and mechanically ventilated by an anesthesia ventilator with a partial rebreathing system, whereby the exhaled gas is recirculated via a $\mathrm{CO}_{2}$ absorber and fresh gas mixture is continuously supplied. The mixing box is inserted in the expiratory limb of the ventilator circuit to collect the expired gas. Inlet 1 is placed at the mouth piece close to the endotracheal tube, for continuous on-line monitoring of breath-to-breath oxygen and carbon dioxide fractional concentrations. This checks that the steady state had not been perturbed. Another two inlets are used for the measurement of $\mathrm{VO}_{2}$. Inlet 2, which is placed in the inspiratory limb of the ventilator circuit, samples inspiratory gas; Inlet 3 samples the 'effluent' mixed expirate from the distal end of the mixing box. 


\subsection{Setup of respiratory mass spectrometer in the ICU with pediatric ventilators}

We have also adapted the AMIS2000 respiratory mass spectrometer in the ICU to various pediatric ventilators with continuous flow (Figure 7). Pediatric ventilators in the ICU use continuous flow to supply fresh gas throughout the breathing cycle. This avoids increasing the amount of work required to trigger spontaneous breathing. In a setup different from the anesthesia ventilator, the mixing box is connected to the exit port of the pediatric ventilator to collect the expired gas, and is also connected to an 'expiratory' inlet (Inlet 3). The expiratory inlet allows sampling of the 'effluent' mixed expirate from the distal end of the mixing box. Inlets 1 and 2 are placed at the mouth piece and in the inspiratory limb respectively, in the same way as in the anesthesia ventilator.

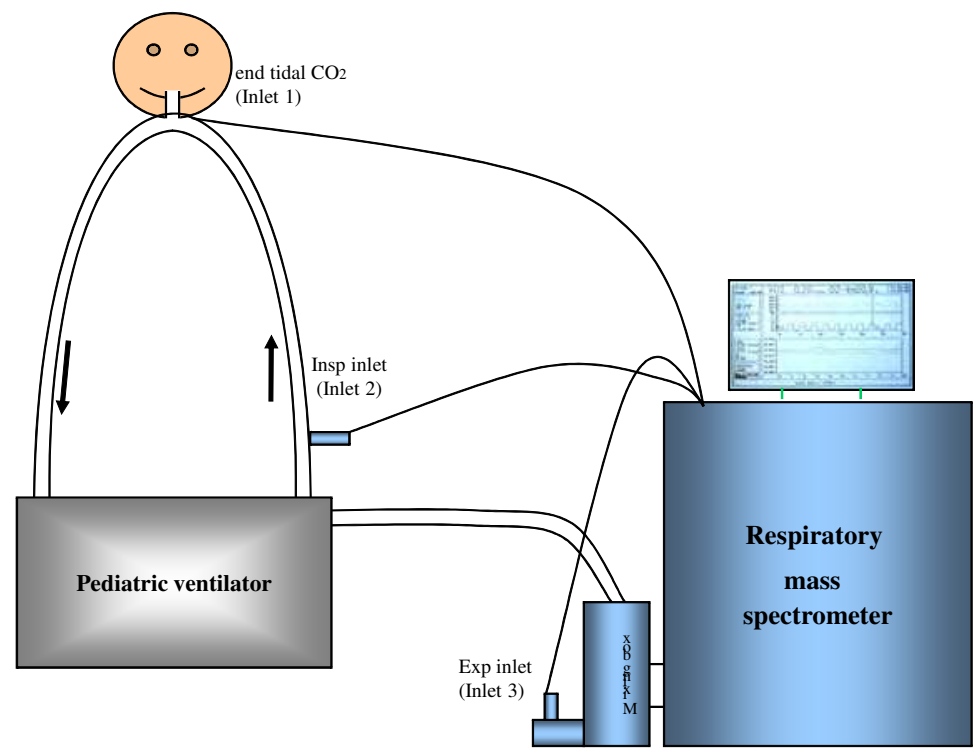

Fig. 7. The setup of the AMIS2000 respiratory mass spectrometer sampling inlets, mixing box, and the circuit of the pediatric ventilator in the ICU.

\subsection{Clinical applications of respiratory mass spectrometry in the ICU}

Respiratory mass spectrometers were first produced for commercial applications in the late 1980s. The reported precision of the mass spectrometer was as low as $5 \%$ in spontaneous breathing at rest or during exercise. The precision increases in paralyzed and ventilated patients. Precision was further improved by avoiding the use of flow sensors. Versatility of the respiratory mass spectrometer is greatly increased by the use of long sampling probes up to 30 meters(Davies and Denison 1979). Long probes allow the study of subjects who otherwise might be inaccessible due to the size of the equipment, such as patients undergoing cardiac catheterization, intensive care, or surgery, where space at the bedside is severely limited. Long probes also enable simultaneous events to be examined sequentially, and permit a single mass spectrometer to be shared between several patients or laboratories. Respiratory mass spectrometers have become valuable clinical research tools. Our adaptation of the respiratory mass spectrometer to pediatric ventilators has allowed us to extensively study systemic hemodynamics and oxygen transport, and the factors affecting them, before and after cardiac 
surgery in children with congenital heart defects (Li, Hoschtitzky et al. 2004; Li, Hoskote et al. 2005; Li, Schulze-Neick et al. 2000; Li, Zhang et al. 2006; Li, Zhang et al. 2006; Li, Zhang et al. 2007; Li, Zhang et al. 2007; Li, Zhang et al. 2008; Zhang 2008; Zhang, Holtby et al. 2008).

The importance of oxygen transport is increasingly appreciated in the care of critically ill patients, particularly after CPB (Gilbert, Haupt et al. 1986; Haupt, Gilbert et al. 1985; Hoffman, Ghanayem et al. 2000; Li, Hoschtitzky et al. 2004; Li, Hoskote et al. 2005; Li, Schulze-Neick et al. 2000; Li, Zhang et al. 2006; Li, Zhang et al. 2006; Li, Zhang et al. 2007; Li, Zhang et al. 2007; Li, Zhang et al. 2008; Oudemans-van Straaten, Jansen et al. 1996; Powers, Mannal et al. 1973; Tweddell, Hoffman et al. 1999; Zhang 2008; Zhang, Holtby et al. 2008). The fundamental requirement of ICU management is to match systemic oxygen delivery $\left(\mathrm{DO}_{2}\right)$ to $\mathrm{VO}_{2}$, to sustain cellular metabolism and end-organ function. Many patients requiring ICU support have reduced $\mathrm{DO}_{2}$, usually as a result of decreased myocardial function. However, in many patients the reduced cardiac output and $\mathrm{DO}_{2}$ are further compounded by secondary abnormalities of $\mathrm{VO}_{2}$ that amplify the deficiency of $\mathrm{DO}_{2}$ and contribute to the overall imbalance of oxygen transport. This combination is seen in many situations such as sepsis and trauma (Gilbert, Haupt et al. 1986; Haupt, Gilbert et al. 1985; Powers, Mannal et al. 1973), but is a consistent feature of cardiac surgery (Hoffman, Ghanayem et al. 2000; Li, Hoschtitzky et al. 2004; Li, Schulze-Neick et al. 2000; Li, Zhang et al. 2007).

Most children experience a phase of reduced cardiac output during the first few hours after CPB (Hoffman, Ghanayem et al. 2000; Li, Zhang et al. 2007; Wernovsky, Wypij et al. 1995). At the same time, $\mathrm{VO}_{2}$ is increased and highly dynamic in relation to central body temperature (Li, Hoschtitzky et al. 2004; Li, Schulze-Neick et al. 2000), the systemic inflammatory response (Li, Hoschtitzky et al. 2004; Oudemans-van Straaten, Jansen et al. 1996), pharmacological manipulations (Hayes, Timmins et al. 1994; Li, Zhang et al. 2006), and ventilatory manipulations ( $\mathrm{Li}$, Hoskote et al. 2005; $\mathrm{Li}$, Zhang et al. 2008). $\mathrm{VO}_{2}$ is an important constituent in the balance of oxygen transport, but has been largely ignored in ICU management. Traditional management of these patients has focused on augmenting myocardial performance through the use of inotropes, for example, to enhance cardiac output and $\mathrm{DO}_{2}$. However, inotropic agents may not effectively enhance cardiac output in the presence of myocardial injury, and may paradoxically stimulate systemic and myocardial oxygen consumption, offsetting any gains in $\mathrm{DO}_{2}$ (Fowler, Alderman et al. 1984; Hayes, Timmins et al. 1994; Li, Zhang et al. 2006). An alternative (and in some ways more rational) approach to improving the balance of oxygen transport may be to decrease $\mathrm{VO}_{2}$. For example, the use of skeletal muscle paralysis and assisted ventilation is a standard therapy directed at reducing metabolic demands. These simple maneuvers may reduce $\mathrm{VO}_{2}$ by up to 20 to $30 \%$ (Nisbet, Dobbinson et al. 1973; Westenskow, Jordan et al. 1978). Similarly, profound reductions in $\mathrm{VO}_{2}$ may be achieved simply by controlling central body temperature. We have shown in infants after cardiac surgery, for example, that central pyrexia increases $\mathrm{VO}_{2}$ by approximately $11 \%$ per degree Celsius (Li, Schulze-Neick et al. 2000). Therefore, in the current conceptualization of oxygen transport, emphasis should shift beyond cardiac output and oxygen delivery to the balance between $\mathrm{DO}_{2}$ and $\mathrm{VO}_{2}$.

\section{Calculation of oxygen transport parameters using directly measured $\mathrm{VO}_{2}$}

\subsection{The Fick principle}

The Fick principle states that 'The total uptake or release of any substance by an organ is the product of blood flow to the organ and the arteriovenous concentration difference of the substance.' (Fick 1870). 
The Fick principle implies that if the flow in a system cannot be measured directly, then it can be measured using an indicator, provided that the indicator is removed at a known rate. Fick described the theory of a method to calculate cardiac output but never actually measured it himself. He argued: 'It is astonishing that no one has arrived at the following obvious method by which the amount of blood ejected by the ventricle of the heart with each systole may be determined directly, at least in animals. One measures how much oxygen an animal absorbs from the air in a given time. During the experiment one obtains a sample of arterial and venous blood; in both the oxygen content is measured. The difference in oxygen content tells how much oxygen each cubic centimeter of blood takes up in its passage through the lungs. As one knows the total quantity of oxygen absorbed in a given time one can calculate how many cubic centimeters of blood passed through the lungs in this time.' (Vandam and Fox 1998).

Verification of the Fick principle in humans was initially accomplished in 1930, through the daring exploits of Baumann and Grollman at a time when cardiac catheterization had yet to be established as a clinical tool. They obtained samples of mixed venous blood by inserting a spinal tap needle just to the right of the sternum; the needle entered the right ventricular chamber by puncturing its wall (Grollman 1932).

The direct Fick principle using $\mathrm{VO}_{2}$ is one of the oldest methods of measuring systemic and pulmonary blood flows, but nonetheless remains the gold standard. It can be used in simple biventricular and varied complex circulations in congenital heart defects, before or after surgical repair palliations. Relevant equations are provided in the following sections.

\subsection{In normal circulation}

The direct Fick method measures cardiac output (CO, which is systemic blood flow, Qs, and is equal to pulmonary blood flow, $\mathrm{Qp}$ ) with $\mathrm{VO}_{2}$ according to the following equation:

$$
\mathrm{CO}=\mathrm{VO}_{2} /\left(\mathrm{CaO}_{2}-\mathrm{CvO}_{2}\right)
$$

where $\mathrm{CaO}_{2}$ and $\mathrm{CvO}_{2}$ are arterial and the mixed venous oxygen contents, respectively. Then:

$$
\begin{gathered}
\mathrm{SVR}=(\mathrm{MaP}-\mathrm{MsvcP}) / \mathrm{CO} \\
\mathrm{PVR}=(\mathrm{MpaP}-\mathrm{MpvP}) / \mathrm{CO} \\
\mathrm{DO}_{2}=\mathrm{CO} \times \mathrm{CaO}_{2} \\
\mathrm{ERO}_{2}=\mathrm{VO}_{2} / \mathrm{DO}_{2}
\end{gathered}
$$

where $\mathrm{MaP}, \mathrm{MsvcP}, \mathrm{MpaP}$, and $\mathrm{MpvP}$ are mean systemic arterial, superior vena cava, pulmonary arterial, and pulmonary venous pressures; $\mathrm{CaO}_{2}$ is systemic arterial oxygen content.

\subsection{In biventricular circulation with shunt}

In a biventricular circulation, the left to right, right to left, or bidirectional shunt may be present at the atrial, ventricular, or great vessel levels, such as in atrial septal defect, ventricular septal defect, patent arterial duct, or tetrology of Fallot.

$$
\begin{gathered}
\mathrm{Qs}=\mathrm{VO}_{2} /\left(\mathrm{CaO}_{2}-\mathrm{CvO}_{2}\right) \\
\mathrm{Qp}=\mathrm{VO}_{2} /\left(\mathrm{CpvO}_{2}-\mathrm{CpaO}_{2}\right)
\end{gathered}
$$




$$
\begin{gathered}
\mathrm{SVR}=(\mathrm{MaP}-\mathrm{MsvcP}) / \mathrm{Qs} \\
\mathrm{PVR}=(\mathrm{MpaP}-\mathrm{MpvP}) / \mathrm{Qp} \\
\mathrm{DO}_{2}=\mathrm{CO} \times \mathrm{CaO}_{2}
\end{gathered}
$$

where $\mathrm{CaO}_{2}, \mathrm{CvO}_{2}$, and $\mathrm{CpvO}_{2}$ are systemic arterial and venous, and pulmonary venous oxygen contents; and $\mathrm{MaP}, \mathrm{MvP}$, and $\mathrm{MpvP}$ are mean systemic arterial, venous, and pulmonary venous pressures. $\mathrm{ERO}_{2}$ is calculated as in the normal circulation (Equation 8).

\subsection{In one-and-a-half ventricular circulation: Bidirectional cavopulmonary shunt}

In bidirectional cavopulmonary shunt circulation, the blood from the superior vena cava is directed to the pulmonary arteries, passing through the pulmonary circulation (Qp) and becomes oxygenated before it reaches the systemic circulation. Once in the systemic circulation, the blood from the superior vena cava mixes with systemic venous blood from the inferior vena cava (Qivc) to form total cardiac output (CO). Therefore, as stated by Salim, Case et al. (1995):

$$
\begin{gathered}
\mathrm{Qsvc}=\mathrm{Qp} \\
\mathrm{CO}=\mathrm{Qp}+\mathrm{Qivc} \\
\mathrm{Qp}=\mathrm{VO}_{2} /\left(\mathrm{CpvO}_{2}-\mathrm{CsvcO}_{2}\right) \\
\mathrm{CO}=\mathrm{VO}_{2} \times\left(\mathrm{CpvO}_{2}-\mathrm{CivcO}_{2}\right) /\left[\left(\mathrm{CpvO}_{2}-\mathrm{CsvcO}_{2}\right) \times\left(\mathrm{CaO}_{2}-\mathrm{CivcO}_{2}\right)\right] \\
\mathrm{Qivc}=\mathrm{CO}-\mathrm{Qp} \\
\mathrm{SVR}=(\mathrm{MaP}-\mathrm{MivcP}) / \mathrm{Qs} \\
\mathrm{PVR}=(\mathrm{MsvcP}-\mathrm{MpvP}) / \mathrm{Qp}
\end{gathered}
$$

where $\mathrm{CaO}_{2}, \mathrm{CivcO}_{2}, \mathrm{CsvcO}_{2}$, and $\mathrm{CpvO}_{2}$ are arterial, inferior and superior vena cava and pulmonary venous oxygen contents; $\mathrm{MaP}, \mathrm{MivcP}, \mathrm{MsvcP}$, and $\mathrm{MpvP}$ are mean systemic arterial, inferior and superior vena cava, and pulmonary venous pressures. $\mathrm{DO}_{2}$ and $\mathrm{ERO}_{2}$ are calculated as in the normal circulation (Equations $7 \& 8$ ).

\subsection{In single ventricular circulation: Hypoplastic left heart syndrome and the Norwood circulation}

In functionally single ventricular circulation, a single outlet from the heart provides both systemic and pulmonary circulations via an interposed B-T shunt or right ventricle to pulmonary artery shunt. Therefore:

$$
\begin{gathered}
\mathrm{CO}=\mathrm{Qs}+\mathrm{Qp} \\
\mathrm{Qs}=\mathrm{VO}_{2} /\left(\mathrm{CaO}_{2}-\mathrm{CvO}_{2}\right) \\
\mathrm{Qp}=\mathrm{VO}_{2} /\left(\mathrm{CpvO}_{2}-\mathrm{CaO}_{2}\right) \\
\mathrm{SVR}=(\mathrm{MaP}-\mathrm{MsvcP}) / \mathrm{Qs}
\end{gathered}
$$




$$
\begin{gathered}
\text { 'PVR' }=(\mathrm{MaP}-\mathrm{MpvP}) / \mathrm{Qp} \\
\text { (including the shunt) } \\
\mathrm{DO}_{2}=\mathrm{Qs} \times \mathrm{CaO}_{2}
\end{gathered}
$$

Where $\mathrm{CaO}_{2}, \mathrm{CvO}_{2}$ and $\mathrm{CpvO}_{2}$ are systemic arterial, superior vena caval and pulmonary venous oxygen contents; $\mathrm{MaP}, \mathrm{MsvcP}$, and $\mathrm{MpvP}$ are mean systemic arterial, superior vena cava, and pulmonary venous pressures; ' $P V R^{\prime}$ is pulmonary vascular resistance including the shunt in the classic Norwood procedure (Li, Zhang et al. 2006; Li, Zhang et al. 2007). $\mathrm{ERO}_{2}$ is calculated as in the normal circulation (Equation 8).

In this Chapter, the Norwood circulation is used as the model to understand the balance of oxygen transport and the factors affecting it. This is an ideal model to understand the concept of oxygen transport, since the Norwood physiology is characterized by profound hemodynamic instability and oxygen transport imbalance, and represents the most challenging group of children for postoperative management after CPB. Data presented in this chapter were obtained in neonates after the classic Norwood procedure with the Blalock-Taussig shunt, but the basic physiology of the classic Norwood procedure is largely the same as the modified procedure with the right ventricle to pulmonary artery conduit, i.e., a single neonatal ventricle provides the parallel pulmonary and systemic circulations.

\section{Improved understanding of the Norwood physiology and postoperative management using direct measurement of $\mathrm{VO}_{2}$}

The Norwood procedure for hypoplastic left heart syndrome, and similar anatomic variants, continues to have significant morbidity, and a mortality rate that ranges from $6 \%$ to $25 \%$ (Azakie, Merklinger et al. 2001; Gaynor, Mahle et al. 2002; Ohye, Sleeper et al. 2010; Sano, Huang et al. 2009). Despite advances in surgical and postoperative management, these infants have little hemodynamic reserve. Instability following repair is inherent in the neonatal single ventricle supplying parallel pulmonary and systemic circulations, and is compounded by the variable effects of $\mathrm{CPB}$ and ischemia and reperfusion injury. Our understanding of the Norwood physiology has been based on theoretical studies using computational models (Barnea, Austin et al. 1994; Migliavacca, Pennati et al. 2001), and on animal models (Kitaichi, Chikugo et al. 2003). Necessarily, these models do not reflect the true functionally single ventricular physiology. In previous studies in humans, arterial superior vena caval oxygen saturations, and their derivations were most commonly used as surrogates of $\mathrm{DO}_{2}$ (Charpie, Dekeon et al. 2001; Hoffman, Ghanayem et al. 2000; Maher, Pizarro et al. 2003; Tweddell, Hoffman et al. 1999). In some human studies, derived values of pulmonary and systemic blood flows have been obtained, but are based on the key assumption of a fixed $\mathrm{VO}_{2}$ of 160 or $180 \mathrm{~mL} / \mathrm{min} / \mathrm{m}^{2}$ (Charpie, Dekeon et al. 2001; Hoffman, Ghanayem et al. 2000; Maher, Pizarro et al. 2003; Tweddell, Hoffman et al. 1999). However, as demonstrated above in section 2.1.1 (Figure 2), postoperative $\mathrm{VO}_{2}$ has wide inter- and intra-patient variability in children (Li, Schulze-Neick et al. 2000; Li, Zhang et al. 2006; Li, Zhang et al. 2007; Li, Zhang et al. 2008). Thus, significant errors may be introduced in the calculation of hemodynamic and oxygen transport indices incorporating fixed values of $\mathrm{VO}_{2}$. The introduction of such errors has greatly limited our understanding of postoperative hemodynamics and oxygen transport in these patients.

The adaptation of the respiratory mass spectrometer (AMIS2000, Innovision A/S, Demark) to continuously measure $\mathrm{VO}_{2}$ allows the measurement of actual values for each element of 
systemic hemodynamics and oxygen transport. Use of actual values has significantly improved our understanding of the Norwood physiology and its postoperative management.

\subsection{Profiles of hemodynamics and oxygen transport after the Norwood procedure}

The Norwood physiology is an ideal model for understanding oxygen transport, since it is characterized by profound hemodynamic instability and oxygen transport imbalance (Li, Zhang et al. 2007). Wide, unstable, inter-individual and intra-individual variations in all the elements of hemodynamics and oxygen transport are observed, particularly on the systemic side (including systemic vascular resistant and blood flow). Pulmonary vascular resistance and blood flow are less variable, due to the mechanical limitation of the Blalock-Taussig shunt in the classic Norwood procedure or to the right ventricle to pulmonary artery shunt in the modified Norwood procedure.

\section{$5.2 \mathrm{VO}_{2}$ and its contribution to the balance of oxygen transport}

Previous studies used assumptions for $\mathrm{VO}_{2}$ of 160 or $180 \mathrm{~mL} / \mathrm{min} / \mathrm{m}^{2}$ to calculate hemodynamics (Charpie, Dekeon et al. 2001; Hoffman, Ghanayem et al. 2000; Maher, Pizarro et al. 2003; Tweddell, Hoffman et al. 1999). Those values are much higher than the directly measured $\mathrm{VO}_{2}$ in our patients, which ranged from 45 to $152 \mathrm{~mL} / \mathrm{min} / \mathrm{m}^{2}$ (Figure 8).
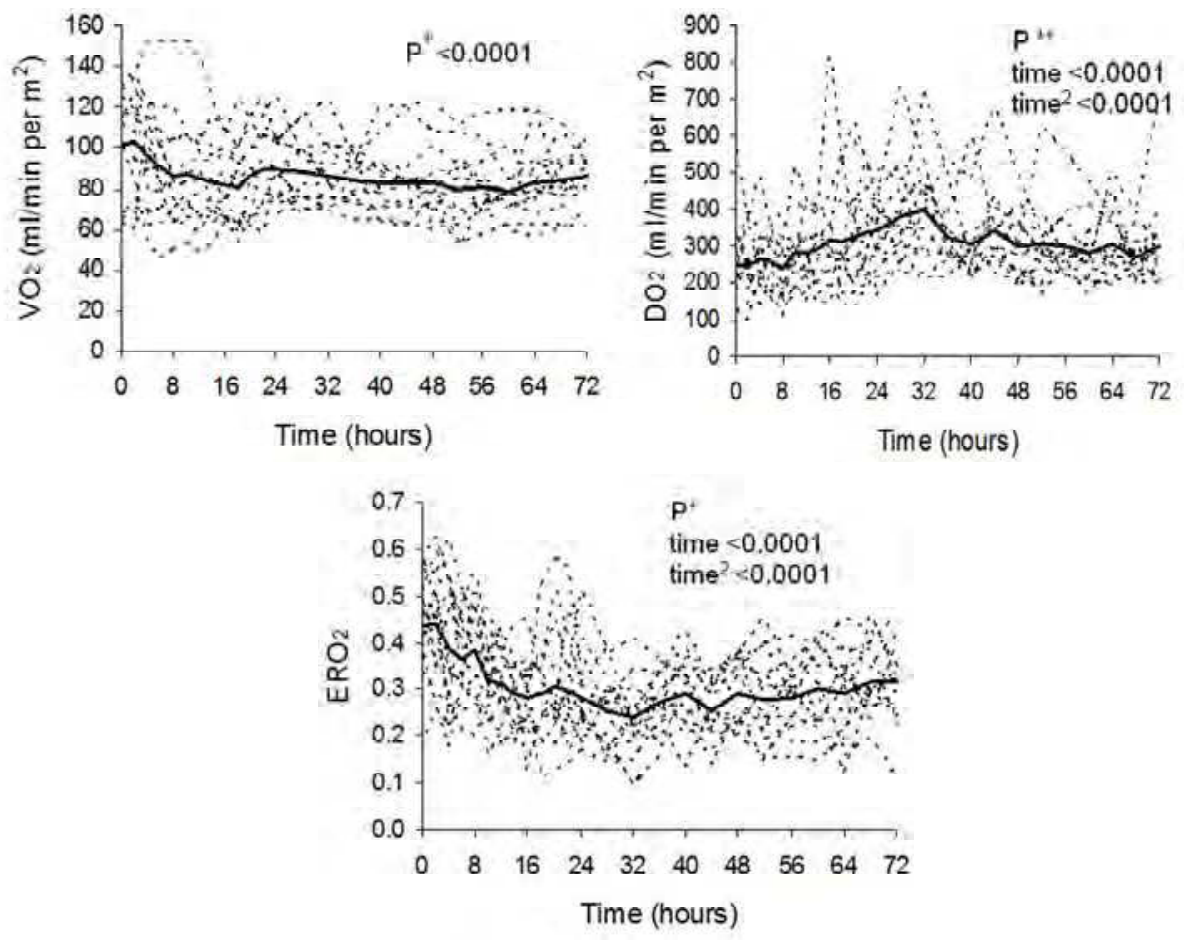

Fig. 8. The changes in oxygen consumption $\left(\mathrm{VO}_{2}\right)$, oxygen delivery $\left(\mathrm{DO}_{2}\right)$ and oxygen extraction ration $\left(\mathrm{ERO}_{2}\right)$ in neonates in the first 72 hours after the Norwood procedure. Dotted lines indicate individual patients; solid line indicates the mean. 
An overestimation of $\mathrm{VO}_{2}$ leads to a direct proportional change in the estimates for the calculated variables. For example, an assumed $\mathrm{VO}_{2}$ of $170 \mathrm{~mL} / \mathrm{min} / \mathrm{m}^{2}$, compared with the measured mean $\mathrm{VO}_{2}$ on arrival in ICU of $101 \mathrm{~mL} / \mathrm{min} / \mathrm{m}^{2}$, leads to a $68 \%$ overestimation of total CO, Qp, and Qs, and a 68\% underestimation of PVR and SVR. Even more important, $\mathrm{VO}_{2}$ is highly variable both between and within individual patients over time. Using a single assumed $\mathrm{VO}_{2}$ makes no provision for the highly dynamic patient milieu that is inherent in the Norwood physiology.

$\mathrm{VO}_{2}$ increases immediately after the Norwood procedure, mainly due to the systemic inflammatory response (Li, Hoschtitzky et al. 2004; Oudemans-van Straaten, Jansen et al. 1996), re-warming from hypothermic CPB and fever (Li, Hoschtitzky et al. 2004; Li, SchulzeNeick et al. 2000), and the use of inotropes (Li, Zhang et al. 2006). After arrival of the patient in the ICU, $\mathrm{VO}_{2}$ decreases rapidly in the first 24 hours, followed by a slower decrease over the following 48 hours. In the first 24 hours, $\mathrm{CO}, \mathrm{Qs}$, and $\mathrm{DO}_{2}$ are the variables most decreased. However, during the critical first 24-hour period, the balance of $\mathrm{VO}_{2}$ and $\mathrm{DO}_{2}$ improves significantly, as indicated by the rapid decrease in $\mathrm{ERO}_{2}$ (Figure 8). The observed improvement in balance results primarily from a decrease in $\mathrm{VO}_{2}$, rather than $\mathrm{DO}_{2}$ as previously reported. After 24 hours, $\mathrm{DO}_{2}$ became the primary contributor to the balance of oxygen transport.

\subsection{Optimizing oxygen delivery}

Historically, the postoperative management strategy for patients after the Norwood procedure was directed at diminishing Qp by increasing PVR, in order to increase Qs and $\mathrm{DO}_{2}$. Analysis of our data reveals that SVR is far more important in determining Qs and $\mathrm{DO}_{2}$ than is PVR. This indicates that both the systemic and pulmonary vascular compartments have variable resistance, but the systemic circulation has a more profound effect on $\mathrm{DO}_{2}$, whereas the pulmonary compartment is relatively fixed with the mechanical limitation of the shunt. Interestingly, increases in $\mathrm{SaO}_{2}$ and $\mathrm{PaO}_{2}$ have only a weak positive correlation with Qp, implying that relative hypoxia to increase PVR and reduce Qp yields little benefit to $\mathrm{DO}_{2}$. Our data also show that hemoglobin is an important contributor to $\mathrm{DO}_{2}$, with a tight correlation between $\mathrm{DO}_{2}$ and hemoglobin values. Therefore, treatment strategies should be designed to improve $\mathrm{DO}_{2}$ and its balance with $\mathrm{VO}_{2}$. Specifically, management strategies to maintain a high hemoglobin value, a low $\mathrm{VO}_{2}$, and a relatively low and stable SVR appear to be rational.

\subsection{Factors that affect the balance of oxygen transport}

Direct measurements of $\mathrm{VO}_{2}$ have allowed us to study the complex effects of some routine treatments on oxygen transport. Some routine treatments used in an effort to improve the balance of oxygen transport in fact have adverse effects.

\subsubsection{Catecholamines}

Catecholamines, such as dopamine, epinephrine, and norepiphrine, are commonly used in patients after $\mathrm{CPB}$ to augment cardiac contractility and $\mathrm{DO}_{2}$ (Kawamura, Minamikawa et al. 1980; Merin, Bitran et al. 1977; Rosenblum and Frieden 1972). Catecholamines also stimulate $\mathrm{VO}_{2}$ through their effects on myocardial work and metabolic rate (Cori and Buchwald 1930; Ensinger, Weichel et al. 1993; Maxwell, Crompton et al. 1985). If the increase in $\mathrm{DO}_{2}$ is greater than the increase in $\mathrm{VO}_{2}$, catecholamines will improve the overall balance of oxygen 
transport and tissue oxygenation. Some reports indicate favorable responses to catecholamine treatment in adults and older children after cardiac surgery (Kawamura, Minamikawa et al. 1980; Merin, Bitran et al. 1977; Rosenblum and Frieden 1972). In neonates, however, catecholamines have additional thermogenic actions through their effects on brown adipose tissue, resulting in an exaggerated increase in $\mathrm{VO}_{2}$ (Maxwell, Crompton et al. 1985; Penny, Sano et al. 2001; Sell, Deshaies et al. 2004). Furthermore, neonatal hearts are known to have limited reserves to increase cardiac contractility. The reserves might become marginal in a Norwood circulation, with the injured single right ventricle providing parallel pulmonary and systemic circulations. In these patients, efforts to improve $\mathrm{DO}_{2}$ by catecholamines are more likely to be associated with predominately adverse effects. As we have reported, terminating a moderate dose of dopamine (5 $\mu \mathrm{g} / \mathrm{kg} / \mathrm{min}$ ) was not associated with any significant changes in $\mathrm{CO}$ or $\mathrm{DO}_{2}$, but with a significant decrease in heart rate and rate-pressure product, an indirect indicator of myocardial oxygen consumption ( $\mathrm{Li}$, Zhang et al. 2006). $\mathrm{VO}_{2}$ also decreased by $16 \pm 14$ $\mathrm{mL} / \mathrm{min} / \mathrm{m}^{2}$, representing a change of $20 \pm 11 \%$. Terminating dopamine resulted overall in an improvement of the balance of oxygen transport, as indicated by the significant decrease in $\mathrm{ERO}_{2}$ (Figure 10). Therefore, a moderate dose of dopamine induces predominantly an increase in $\mathrm{VO}_{2}$, adversely affecting the $\mathrm{VO}_{2}-\mathrm{DO}_{2}$ relationship. Figure 11 shows examples of on-line $\mathrm{VO}_{2}$ monitoring before and after dopamine termination.
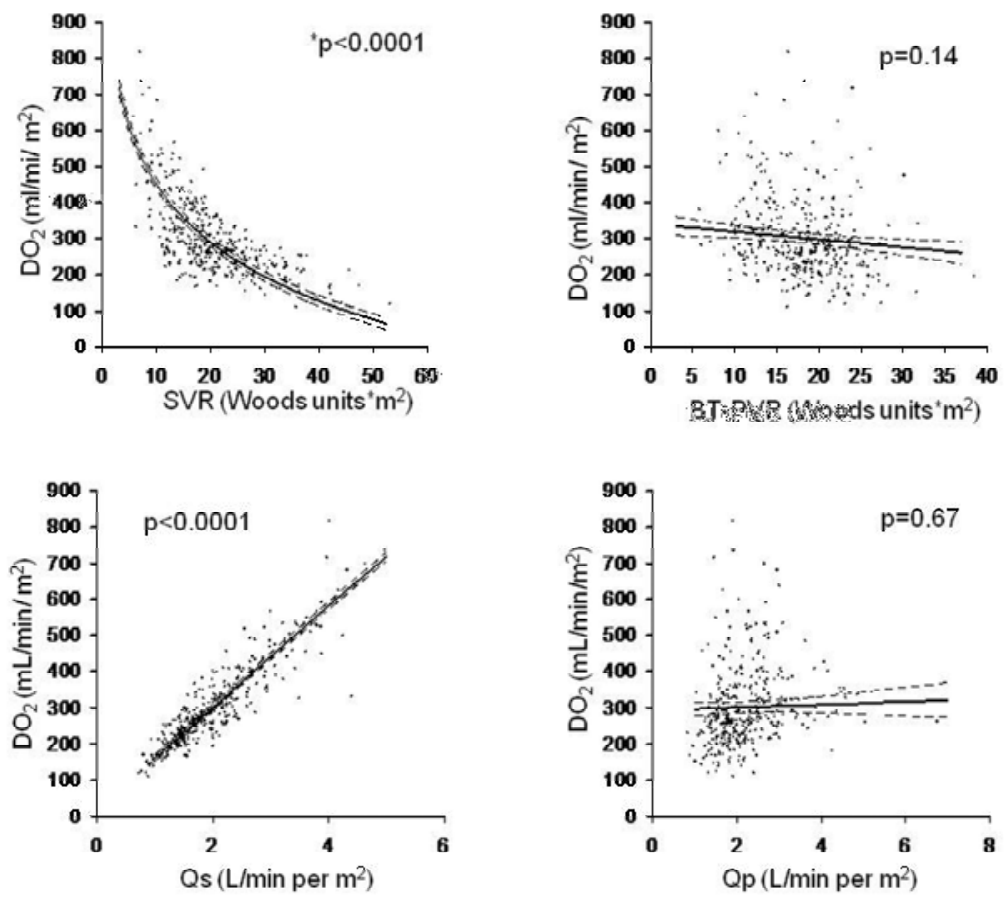

Fig. 9. Correlations between oxygen delivery $\left(\mathrm{DO}_{2}\right)$ and systemic vascular resistance (SVR), systemic blood flow (Qs), total pulmonary vascular resistance including the B-T shunt (BTPVR), and pulmonary blood flow (Qp). 

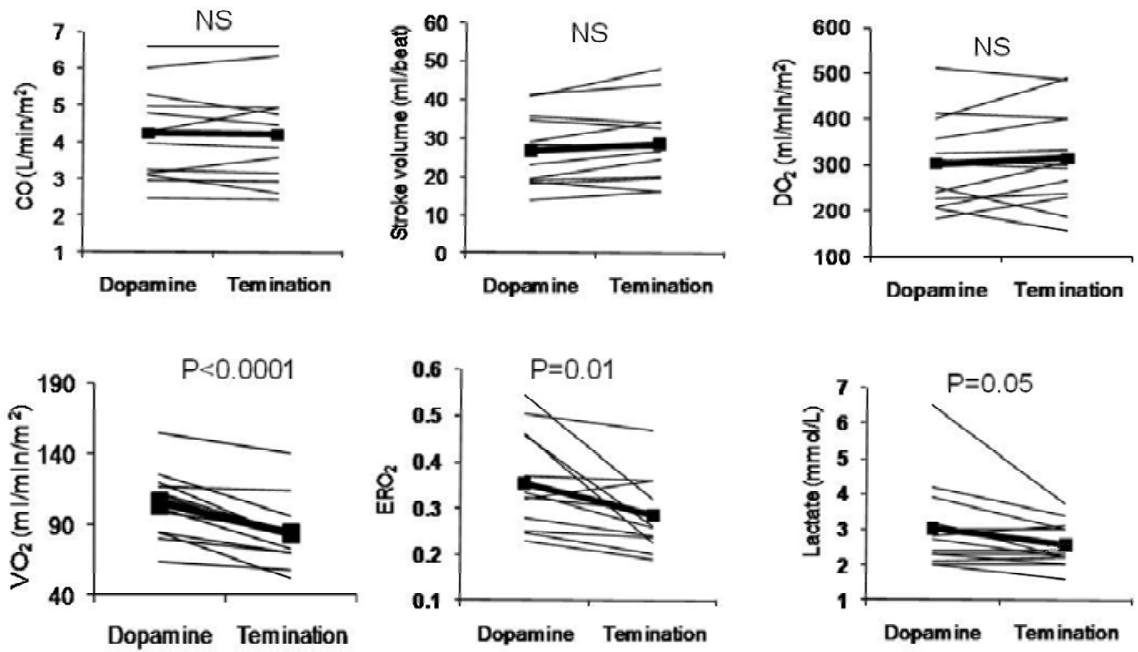

Fig. 10. The individual (thin line) and mean (bold line) changes in systemic hemodynamics and oxygen transport before and after termination of dopamine following the Norwood procedure.
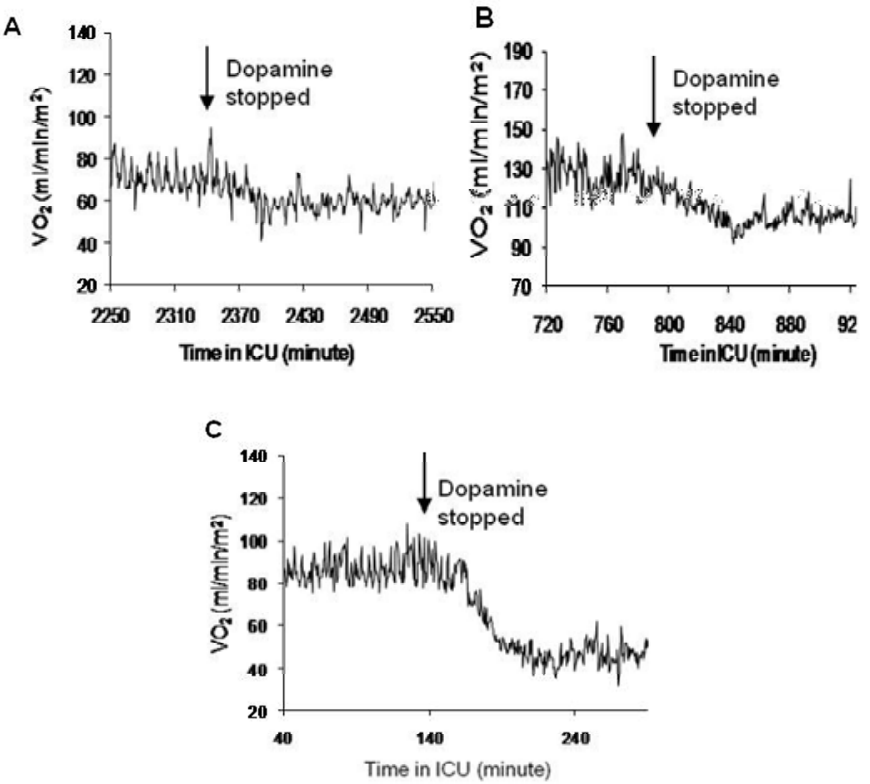

Fig. 11. Examples of the on-line measurement of oxygen consumption $\left(\mathrm{VO}_{2}\right)$ in three patients showing rapid and (A) small, (B) moderate, and (C) large decreases in $\mathrm{VO}_{2}$ after terminating dopamine. 


\subsection{2 $\mathrm{CO}_{2}$}

$\mathrm{CO}_{2}$ has been suggested as a factor increasing $\mathrm{DO}_{2}$ in neonates both before and after the Norwood procedure (Bradley, Simsic et al. 2001; Mora, Pizarro et al. 1994). Consequently, it is a common practice to maintain a relatively high arterial $\mathrm{CO}_{2}$ tension $\left(\mathrm{PaCO}_{2}\right)$, primarily by hypoventilation. The potent pulmonary vasoconstrictive effect of $\mathrm{CO}_{2}$ was believed to decrease pulmonary blood flow (Qp), thereby increasing Qs (Mora, Pizarro et al. 1994). We studied the effect of stepwise increases in $\mathrm{PaCO}_{2}$ from 40 to 50 to $60 \mathrm{mmHg}$, and found complex effects of $\mathrm{CO}_{2}$ on systemic and regional oxygen transport ( $\mathrm{Li}$, Zhang et al. 2008). Moderate hypercapnia increases Qs as a result of its effect on SVR, rather than via PVR as previously proposed. The increase in systemic blood flow is primarily a consequence of increased cerebral blood flow that compromises splanchnic circulation. Moderate hypercapnia also decreases $\mathrm{VO}_{2}$ and stimulates the release of catecholamines. The decrease in $\mathrm{VO}_{2}$ improves the balance of oxygen transport, but the increase in catecholamines may be undesirable (Figures 12). Clinically, $\mathrm{CO}_{2}$ should be used with caution when the aim is to improve oxygen delivery.
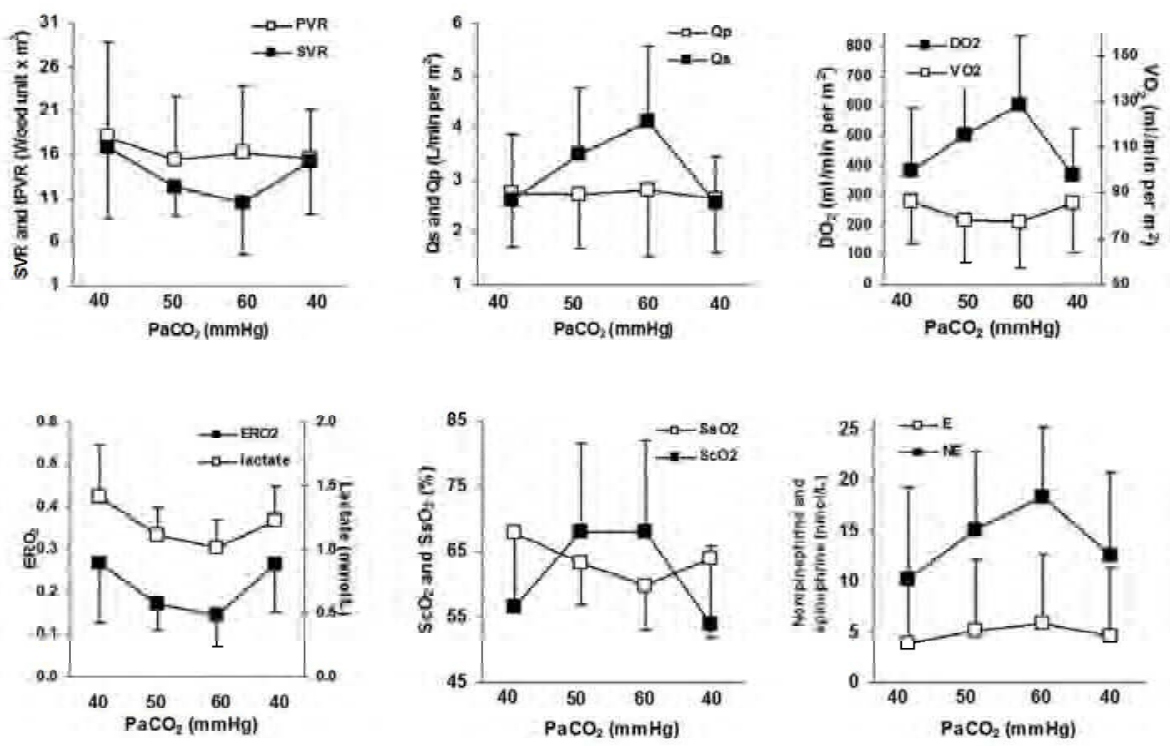

Fig. 12. During stepwise increases in $\mathrm{PaCO}_{2}$ from 40 to 50 to $60 \mathrm{mmHg}$ and after termination of $\mathrm{CO}_{2}$, changes in systemic and total pulmonary vascular resistances (SVR and PVR), systemic and pulmonary blood flow (Qp and Qs), oxygen consumption and delivery $\left(\mathrm{VO}_{2}\right.$ and $\left.\mathrm{DO}_{2}\right)$, oxygen extraction ration $\left(\mathrm{ERO}_{2}\right)$, and lactate, cerebral and splanchnic oxygen saturations $\left(\mathrm{ScO}_{2}\right.$ and $\left.\mathrm{SsO}_{2}\right)$ and in epinephrine and norepinephrine.

\subsubsection{Hyperglycemia}

Hyperglycemia has been identified as a risk factor for adverse outcomes in critically ill patients, including those after $\mathrm{CPB}$. Tight glucose control with insulin therapy has been shown to improve outcomes, but is not common practice for children following CPB. In our 
data, elevated glucose level showed negative correlations with $\mathrm{CO}$ and $\mathrm{DO}_{2}$, and positive correlations with SVR and $\mathrm{ERO}_{2}$ (Figure 13) (Zhang 2008). Therefore, hyperglycemia is
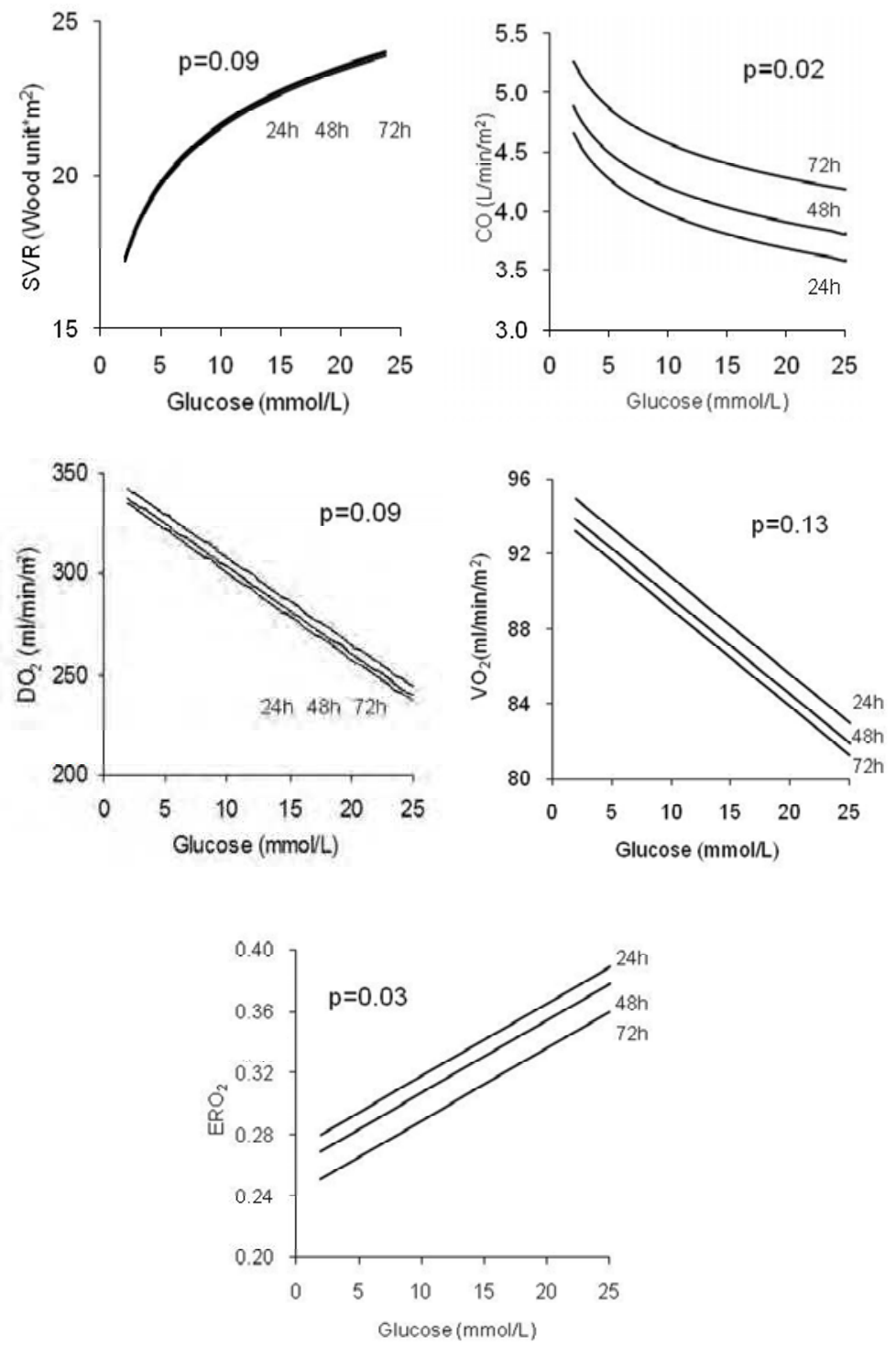

Fig. 13. Representative regression lines for the model predicting correlations between blood glucose and systemic vascular resistance (SVR), cardiac output (CO), systemic oxygen delivery $\left(\mathrm{DO}_{2}\right)$, oxygen consumption $\left(\mathrm{VO}_{2}\right)$, and oxygen extraction $\left(\mathrm{ERO}_{2}\right)$, at 24,48 , and 72 hours after the Norwood procedure for 17 neonates in the ICU. 
negatively associated with systemic hemodynamics and oxygen transport status. Randomized clinical trials of glucose control with insulin therapy are warranted to identify the cause-and-effect relationship and to provide important information regarding appropriate glucose management strategies for children following $\mathrm{CPB}$.

\subsubsection{Other factors}

To date, we have found a few factors in current routine postoperative management that have varied effects on oxygen transport. Further investigations are required to identify other factors in clinical management with favourable or adverse effects, and to design new treatment strategies to improve postoperative oxygen transport and clinical outcomes.

\section{Conclusion}

The predictive equations currently in use are unacceptable to measure $\mathrm{VO}_{2}$ in ventilated children with congenital heart disease, particularly in those younger than 3 years of age, and in the early postoperative period after CPB. Direct, continuous, and precise measurement of $\mathrm{VO}_{2}$ is fundamental for accurate assessments of hemodynamics and oxygen transport in children undergoing cardiac catheterization and in the ICU after cardiac surgery. Respiratory mass spectrometry is the 'state-of-the-art' method, allowing highly sensitive and precise measurement of $\mathrm{VO}_{2}$. Measured $\mathrm{VO}_{2}$ and the Fick principle allow the calculation of each parameter of systemic hemodynamic and oxygen transport, in varied circulations in congenital heart defects, both before and after complete surgical repair or palliation. These actual measurements are not only useful in clinical management, but important for bedside physiological studies on the balance of systemic oxygen transport in children after $\mathrm{CPB}$. Some routine treatments in current use are intended to improve the balance of oxygen transport, but may actually worsen it. When considering clinical management of unbalanced oxygen transport, clinicians should choose therapies that address both decreased $\mathrm{DO}_{2}$ and increased $\mathrm{VO}_{2}$. ICU management strategies need to be refined to optimize the balance of systemic oxygen transport in children with congenital heart defects undergoing cardiac surgery. The resultant improved clinical outcomes in the early postoperative period and at long term follow-up will improve the quality of life for these vulnerable children.

\section{References}

Azakie, T., S. L. Merklinger, et al. (2001). "Evolving strategies and improving outcomes of the modified norwood procedure: a 10-year single-institution experience." Ann Thorac Surg 72(4): 1349-1353.

Barnea, O., E. H. Austin, et al. (1994). "Balancing the circulation: theoretic optimization of pulmonary/systemic flow ratio in hypoplastic left heart syndrome." J Am Coll Cardiol 24(5): 1376-1381.

Bradley, S. M., J. M. Simsic, et al. (2001). "Hemodynamic effects of inspired carbon dioxide after the Norwood procedure." Ann Thorac Surg 72(6): 2088-2093; discussion 20932084. 
Charpie, J. R., M. K. Dekeon, et al. (2001). "Postoperative hemodynamics after Norwood palliation for hypoplastic left heart syndrome." Am J Cardiol 87(2): 198-202.

Chiara, O., P. P. Giomarelli, et al. (1987). "Hypermetabolic response after hypothermic cardiopulmonary bypass." Crit Care Med 15(11): 995-1000.

Cori, C. F. and K. W. Buchwald (1930). "Effect of continuous injection epinephrine on the carbohydrate metabolism, basal metabolism and vascular system of normal man." Am J Physiol(95).

Davies, N. J. and D. M. Denison (1979). "The measurement of metabolic gas exchange and minute volume by mass spectrometry alone." Respir Physiol 36(2): 261-267.

Davies, N. J. and D. M. Denison (1979). "The uses of long sampling probes in respiratory mass spectrometry." Respir Physiol 37(3): 335-346.

Ensinger, H., T. Weichel, et al. (1993). "Effects of norepinephrine, epinephrine, and dopamine infusions on oxygen consumption in volunteers." Crit Care Med 21(10): 1502-1508.

Fick, A. (1870). "U '. ber die Messung des Blutquantums in der Herzventrikeln." Sitzungsberichte der physikalisch-medicinischen Gesellschaftzu Wurtzberg: XVIXVII.

Fomon, S. J., F. Haschke, et al. (1982). "Body composition of reference children from birth to age 10 years." Am J Clin Nutr 35(5 Suppl): 1169-1175.

Fowler, M. B., E. L. Alderman, et al. (1984). "Dobutamine and dopamine after cardiac surgery: greater augmentation of myocardial blood flow with dobutamine." Circulation 70(3 Pt 2): I103-111.

Gaynor, J. W., W. T. Mahle, et al. (2002). "Risk factors for mortality after the Norwood procedure." Eur J Cardiothorac Surg 22(1): 82-89.

Gentles, T. L., K. Gauvreau, et al. (1997). "Functional outcome after the Fontan operation: factors influencing late morbidity." J Thorac Cardiovasc Surg 114(3): 392-403; discussion 404-395.

Gentles, T. L., J. E. Mayer, Jr., et al. (1997). "Fontan operation in five hundred consecutive patients: factors influencing early and late outcome." J Thorac Cardiovasc Surg 114(3): 376-391.

Gilbert, E. M., M. T. Haupt, et al. (1986). "The effect of fluid loading, blood transfusion, and catecholamine infusion on oxygen delivery and consumption in patients with sepsis." Am Rev Respir Dis 134(5): 873-878.

Grollman, A. (1932). The Cardiac Output in Man in Health and Disease. Springfield, Illinois, Charles C Thomas.

Haupt, M. T., E. M. Gilbert, et al. (1985). "Fluid loading increases oxygen consumption in septic patients with lactic acidosis." Am Rev Respir Dis 131(6): 912-916.

Hayes, M. A., A. C. Timmins, et al. (1994). "Elevation of systemic oxygen delivery in the treatment of critically ill patients." N Engl J Med 330(24): 1717-1722.

Hoffman, G. M., N. S. Ghanayem, et al. (2000). "Venous saturation and the anaerobic threshold in neonates after the Norwood procedure for hypoplastic left heart syndrome." Ann Thorac Surg 70(5): 1515-1520; discussion 1521.

Hoskote, A., J. Li, et al. (2004). "The effects of carbon dioxide on oxygenation and systemic, cerebral, and pulmonary vascular hemodynamics after the bidirectional superior cavopulmonary anastomosis." J Am Coll Cardiol 44(7): 1501-1509. 
Kawamura, M., O. Minamikawa, et al. (1980). "Combined use of phenoxybenzamine and dopamine for low cardiac output syndrome in children at withdrawal from cardiopulmonary bypass." Br Heart J 43(4): 388-392.

Kendrick, A. H., J. West, et al. (1988). "Direct Fick cardiac output: are assumed values of oxygen consumption acceptable?" Eur Heart J 9(3): 337-342.

Kitaichi, T., F. Chikugo, et al. (2003). "Suitable shunt size for regulation of pulmonary blood flow in a canine model of univentricular parallel circulations." J Thorac Cardiovasc Surg 125(1): 71-78.

LaFarge, C. G. and O. S. Miettinen (1970). "The estimation of oxygen consumption." Cardiovasc Res 4(1): 23-30.

Laitinen, P. O. and J. Rasanen (1998). "Measured versus predicted oxygen consumption in children with congenital heart disease." Heart 80(6): 601-605.

Li, J., A. Bush, et al. (2003). "Measured versus estimated oxygen consumption in ventilated patients with congenital heart disease: the validity of predictive equations." Crit Care Med 31(4): 1235-1240.

Li, J., A. Hoschtitzky, et al. (2004). "An analysis of oxygen consumption and oxygen delivery in euthermic infants after cardiopulmonary bypass with modified ultrafiltration." Ann Thorac Surg 78(4): 1389-1396.

Li, J., A. Hoskote, et al. (2005). "Effect of carbon dioxide on systemic oxygenation, oxygen consumption, and blood lactate levels after bidirectional superior cavopulmonary anastomosis." Crit Care Med 33(5): 984-989.

Li, J., I. Schulze-Neick, et al. (2000). "Oxygen consumption after cardiopulmonary bypass surgery in children: determinants and implications." J Thorac Cardiovasc Surg 119(3): 525-533.

Li, J., J. Stokoe, et al. (2004). "Continuous measurement of oxygen consumption during cardiopulmonary bypass: description of the method and in vivo observations." Ann Thorac Surg 77(5): 1671-1677.

Li, J., G. Zhang, et al. (2007). "Comparison of the profiles of postoperative systemic hemodynamics and oxygen transport in neonates after the hybrid or the Norwood procedure: a pilot study." Circulation 116(11 Suppl): I179-187.

Li, J., G. Zhang, et al. (2008). "Energy expenditure and caloric and protein intake in infants following the Norwood procedure." Pediatr Crit Care Med 9(1): 55-61.

Li, J., G. Zhang, et al. (2008). "Carbon dioxide--a complex gas in a complex circulation: its effects on systemic hemodynamics and oxygen transport, cerebral, and splanchnic circulation in neonates after the Norwood procedure." J Thorac Cardiovasc Surg 136(5): 1207-1214.

Li, J., G. Zhang, et al. (2008). "Significant correlation of comprehensive Aristotle score with total cardiac output during the early postoperative period after the Norwood procedure." J Thorac Cardiovasc Surg 136(1): 123-128.

Li, J., G. Zhang, et al. (2008). "The influence of systemic hemodynamics and oxygen transport on cerebral oxygen saturation in neonates after the Norwood procedure." J Thorac Cardiovasc Surg 135(1): 83-90, 90 e81-82.

Li, J., G. Zhang, et al. (2006). "Adverse effects of dopamine on systemic hemodynamic status and oxygen transport in neonates after the Norwood procedure." J Am Coll Cardiol 48(9): 1859-1864. 
Li, J., G. Zhang, et al. (2006). "Inclusion of oxygen consumption improves the accuracy of arterial and venous oxygen saturation interpretation after the Norwood procedure." J Thorac Cardiovasc Surg 131(5): 1099-1107.

Li, J., G. Zhang, et al. (2007). "Profiles of hemodynamics and oxygen transport derived by using continuous measured oxygen consumption after the Norwood procedure." J Thorac Cardiovasc Surg 133(2): 441-448.

Lindahl, S. G. (1989). "Oxygen consumption and carbon dioxide elimination in infants and children during anaesthesia and surgery." Br J Anaesth 62(1): 70-76.

Lundell, B. P., M. L. Casas, et al. (1996). "Oxygen consumption in infants and children during heart catheterization." Pediatr Cardiol 17(4): 207-213.

Maher, K. O., C. Pizarro, et al. (2003). "Hemodynamic profile after the Norwood procedure with right ventricle to pulmonary artery conduit." Circulation 108(7): 782-784.

Mair, D. D., D. J. Hagler, et al. (1990). "Fontan operation in 176 patients with tricuspid atresia. Results and a proposed new index for patient selection." Circulation 82(5 Suppl): IV164-169.

Maxwell, G., S. Crompton, et al. (1985). "The effect of dopamine upon oxidative metabolism of brown fat adipocytes." Eur J Pharmacol 116(3): 293-297.

Merin, G., D. Bitran, et al. (1977). "The hemodynamic effects of dopamine following cardiopulmonary bypass." Ann Thorac Surg 23(4): 361-363.

Migliavacca, F., G. Pennati, et al. (2001). "Modeling of the Norwood circulation: effects of shunt size, vascular resistances, and heart rate." Am J Physiol Heart Circ Physiol 280(5): H2076-2086.

Mora, G. A., C. Pizarro, et al. (1994). "Experimental model of single ventricle. Influence of carbon dioxide on pulmonary vascular dynamics." Circulation 90(5 Pt 2): II43-46.

Moukarzel, A. A., J. S. Salas, et al. (2003). "Estimate of specific energy expenditure of fat-free mass and fat mass in children receiving total parenteral nutrition." J Med Liban 51(4): 206-210.

Nisbet, H. I., T. L. Dobbinson, et al. (1973). "Oxygen uptake in ventilated children during methoxyflurane anaesthesia." Can Anaesth Soc J 20(3): 334-346.

Ohye, R. G., L. A. Sleeper, et al. (2010). "Comparison of shunt types in the Norwood procedure for single-ventricle lesions." N Engl J Med 362(21): 1980-1992.

Oudemans-van Straaten, H. M., P. G. Jansen, et al. (1996). "Increased oxygen consumption after cardiac surgery is associated with the inflammatory response to endotoxemia." Intensive Care Med 22(4): 294-300.

Penny, D. J., T. Sano, et al. (2001). "Increased systemic oxygen consumption offsets improved oxygen delivery during dobutamine infusion in newborn lambs." Intensive Care Med 27(9): 1518-1525.

Powers, S. R., Jr., R. Mannal, et al. (1973). "Physiologic consequences of positive endexpiratory pressure (PEEP) ventilation." Ann Surg 178(3): 265-272.

Rosenblum, R. and J. Frieden (1972). "Intravenous dopamine in the treatment of myocardial dysfunction after open-heart surgery." Am Heart J 83(6): 743-748.

Rutledge, J., A. Bush, et al. (2010). "Validity of the LaFarge equation for estimation of oxygen consumption in ventilated children with congenital heart disease younger than 3 years--A revisit." American Heart Journal 160(1): 109-114. 
Salim, M. A., C. L. Case, et al. (1995). "Pulmonary/systemic flow ratio in children after cavopulmonary anastomosis." J Am Coll Cardiol 25(3): 735-738.

Sano, S., S. C. Huang, et al. (2009). "Risk factors for mortality after the Norwood procedure using right ventricle to pulmonary artery shunt." Ann Thorac Surg 87(1): 178-185; discussion 185-176.

Schulze-Neick, I., J. Li, et al. (2001). "Pulmonary vascular resistance after cardiopulmonary bypass in infants: effect on postoperative recovery." J Thorac Cardiovasc Surg 121(6): 1033-1039.

Schulze-Neick, I., J. Li, et al. (2002). "The endothelin antagonist BQ123 reduces pulmonary vascular resistance after surgical intervention for congenital heart disease." J Thorac Cardiovasc Surg 124(3): 435-441.

Sell, H., Y. Deshaies, et al. (2004). "The brown adipocyte: update on its metabolic role." Int J Biochem Cell Biol 36(11): 2098-2104.

Shanahan, C. L., N. J. Wilson, et al. (2003). "The influence of measured versus assumed uptake of oxygen in assessing pulmonary vascular resistance in patients with a bidirectional Glenn anastomosis." Cardiol Young 13(2): 137-142.

Shekerdemian, L. S., A. Bush, et al. (1997). "Cardiopulmonary interactions in healthy children and children after simple cardiac surgery: the effects of positive and negative pressure ventilation." Heart 78(6): 587-593.

Shekerdemian, L. S., A. Bush, et al. (1997). "Cardiopulmonary interactions after Fontan operations: augmentation of cardiac output using negative pressure ventilation." Circulation 96(11): 3934-3942.

Tweddell, J. S., G. M. Hoffman, et al. (1999). "Phenoxybenzamine improves systemic oxygen delivery after the Norwood procedure." Ann Thorac Surg 67(1): 161-167; discussion 167-168.

Vandam, L. D. and J. A. Fox (1998). "Adolf Fick (1829-1901), physiologist: a heritage for anesthesiology and critical care medicine." Anesthesiology 88(2): 514-518.

Wernovsky, G., D. Wypij, et al. (1995). "Postoperative course and hemodynamic profile after the arterial switch operation in neonates and infants. A comparison of lowflow cardiopulmonary bypass and circulatory arrest." Circulation 92(8): 22262235.

Wessel, H. U., D. Rorem, et al. (1969). "Continuous determination of oxygen uptake in sedated infants and children during cardiac catheterization." Am J Cardiol 24(3): 376-385.

Westenskow, D. R., W. S. Jordan, et al. (1978). "Correlation of oxygen uptake and cardiovascular dynamics during N2O-fentanyl and N2O-thiopental anesthesia in the dog." Anesth Analg 57(1): 37-41.

Wolf, A., M. J. Pollman, et al. (1998). "Use of assumed versus measured oxygen consumption for the determination of cardiac output using the Fick principle." Cathet Cardiovasc Diagn 43(4): 372-380.

Zhang, G., H. Holtby, et al. (2008). "Aortic atresia is associated with an inferior postoperative systemic, cerebral and splanchnic oxygen transport status in neonates with hypoplastic left heart syndrome after the Norwood procedure. ." Circulation 118(Suppl). 
Zhang, G. M., M; Holtby, H; Cai,S; Van Arsdell,G; Li,J (2008). "Blood Glucose Negatively Correlates with Systemic Hemodynamics and Oxygen Transport and Cerebral Oxygenation in Neonates after the Norwood Procedure." Circulation 118(Suppl.): 913. 


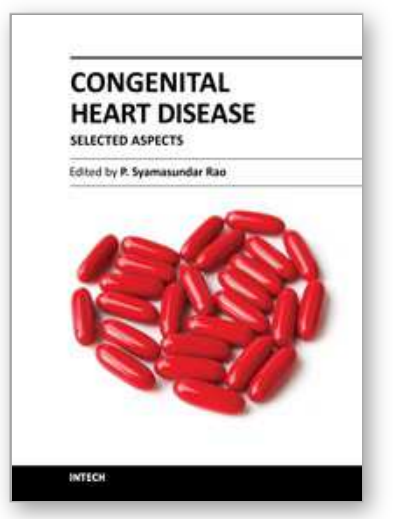

\author{
Congenital Heart Disease - Selected Aspects \\ Edited by Prof. P. Syamasundar Rao
}

ISBN 978-953-307-472-6

Hard cover, 348 pages

Publisher InTech

Published online 18, January, 2012

Published in print edition January, 2012

There are significant advances in the understanding of the molecular mechanisms of cardiac development and the etiology of congenital heart disease (CHD). However, these have not yet evolved to such a degree so as to be useful in preventing $\mathrm{CHD}$ at this time. Developments such as early detection of the neonates with serious heart disease and their rapid transport to tertiary care centers, availability of highly sensitive noninvasive diagnostic tools, advances in neonatal care and anesthesia, progress in transcatheter interventional procedures and extension of complicated surgical procedures to the neonate and infant have advanced to such a degree that almost all congenital cardiac defects can be diagnosed and "corrected". Treatment of the majority of acyanotic and simpler cyanotic heart defects with currently available transcatheter and surgical techniques is feasible, effective and safe. The application of staged total cavo-pulmonary connection (Fontan) has markedly improved the long-term outlook of children who have one functioning ventricle. This book, I hope, will serve as a rich source of information to the physician caring for infants, children and adults with CHD which may help them provide optimal care for their patients.

\title{
How to reference
}

In order to correctly reference this scholarly work, feel free to copy and paste the following:

Jia Li (2012). Accurate Measurement of Systemic Oxygen Consumption in Ventilated Children with Congenital Heart Disease, Congenital Heart Disease - Selected Aspects, Prof. P. Syamasundar Rao (Ed.), ISBN: 978-953307-472-6, InTech, Available from: http://www.intechopen.com/books/congenital-heart-disease-selectedaspects/accurate-measurement-of-systemic-oxygen-consumption-in-ventilated-children-with-congenital-heartdis

\section{INTECH}

open science | open minds

\section{InTech Europe}

University Campus STeP Ri

Slavka Krautzeka 83/A

51000 Rijeka, Croatia

Phone: +385 (51) 770447

Fax: +385 (51) 686166

www.intechopen.com

\section{InTech China}

Unit 405, Office Block, Hotel Equatorial Shanghai

No.65, Yan An Road (West), Shanghai, 200040, China

中国上海市延安西路65号上海国际贵都大饭店办公楼 405 单元

Phone: +86-21-62489820

Fax: $+86-21-62489821$ 
(C) 2012 The Author(s). Licensee IntechOpen. This is an open access article distributed under the terms of the Creative Commons Attribution 3.0 License, which permits unrestricted use, distribution, and reproduction in any medium, provided the original work is properly cited. 